\title{
Drivers of extreme wind events in Mexico for wind power applications
}

\section{Article}

Published Version

Creative Commons: Attribution 4.0 (CC-BY)

Open Access

Thomas, S. R., Martinez-Alvarado, O. ORCID:

https://orcid.org/0000-0002-5285-0379, Drew, D. and

Bloomfield, H. ORCID: https://orcid.org/0000-0002-5616-1503

(2021) Drivers of extreme wind events in Mexico for wind power applications. International Journal of Climatology, 41 (S1). E2321-E2340. ISSN 0899-8418 doi:

https://doi.org/10.1002/joc.6848 Available at https://centaur.reading.ac.uk/92874/

It is advisable to refer to the publisher's version if you intend to cite from the work. See Guidance on citing.

To link to this article DOI: http://dx.doi.org/10.1002/joc.6848

Publisher: John Wiley \& Sons

All outputs in CentAUR are protected by Intellectual Property Rights law, including copyright law. Copyright and IPR is retained by the creators or other copyright holders. Terms and conditions for use of this material are defined in the End User Agreement.

\section{www.reading.ac.uk/centaur}




\section{CentAUR}

Central Archive at the University of Reading

Reading's research outputs online 


\title{
Drivers of extreme wind events in Mexico for windpower applications
}

\author{
Simon Richard Thomas ${ }^{1}$ (1) | Oscar Martínez-Alvarado ${ }^{1}$ () | Daniel Drew $^{2}$ | \\ Hannah Bloomfield ${ }^{2}$
}

\begin{abstract}
${ }^{1}$ National Centre for Atmospheric Science, Department of Meteorology, University of Reading, Reading, UK

${ }^{2}$ Department of Meteorology, University of Reading, Reading, UK
\end{abstract}

\section{Correspondence}

Simon Richard Thomas, National Centre for Atmospheric Science, Department of Meteorology, University of Reading, Reading RG6 6BB, UK.

Email: s.r.thomas@reading.ac.uk

Funding information

Newton Fund Institutional, Grant/Award Number: 432335407

\begin{abstract}
In this study, we use a k-mean clustering approach to investigate the weather patterns responsible for extreme wind speed events throughout Mexico using 40 years of the ERA- 5 atmospheric reanalysis. Generally, we find a large geographical split between the weather patterns that generate the strongest winds across the country. The highest wind power production periods therefore occur at different times in different regions across the country. In the South, these are associated with cold surge events, where an anticyclone is present in the Gulf of Mexico resulting in a strong Northerly flow across the Isthmus of Tehuantepec. In the North-East, Easterly trade winds are responsible for the strongest wind events, whereas in the North-West, it is the proximity of the North Pacific High. However, the weakest winds and lowest power production periods occur at the same times for all stations with the exception of Baja California Sur, meaning that low wind power production may be unavoidable at these times. The El Niño Southern Oscillation is found to influence wind speeds at some locations across Mexico at sub-seasonal time-scales. We report that statistically stronger wind speeds are observed during the Summer during El Niño months than during La Niña months for both sites in Chiapas and Oaxaca.
\end{abstract}

\section{K E Y W O R D S}

application/context, geographic/climatic zone, physical phenomenon, renewable energy, seasonal, severe weather, tools and methods

\section{1 | INTRODUCTION}

The threat of climate change is prompting action across the globe with many countries, including Mexico, investing in renewable energy sources such as wind and solar power. To be able to forecast the conditions for optimum wind power production for a region, it is useful to characterize the dominant weather patterns that drive the near-surface winds across the country (van der Wiel et al., 2019). However, a consensus is yet to be met regarding the weather patterns that drive wind variability across Mexico. This is largely due to the lack of continuous observations across the country specifically designed for wind power research and the limited utilization of numerical weather predictions models and atmospheric reanalyses for this purpose. In this study, we utilize one

This is an open access article under the terms of the Creative Commons Attribution License, which permits use, distribution and reproduction in any medium, provided 
intensive observation period of winds across selected sites across Mexico, funded by the United Nations Development Programme Global Environmental Finance (UNDP-GEF) Unit and implemented by Mexico's Instituto de Investigaciones Eléctricas (now Instituto Nacional de Electricidad y Energías Limpias) UNDP (2012), and motivated by the wind power industry. The field campaign ran between 2005 and 2007 giving reliable anemometric observations over at least two heights. Here, we aim to use these reliable observations to calibrate winds from the ERA-5 atmospheric reanalyses to be able to deduce the weather patterns driving near-surface winds in Mexico.

Extreme wind events play a big role in providing sustained periods of either high or very low wind power production and so are of huge interest to the wind energy community. Here, we focus on extreme wind events observed at the El Progreso site in the state of Chiapas, which is marked as "CI01" on Figure 1. This is because this site is located at a wind farm for which wind power data is also available. Furthermore, El Progreso is located within the low-lying region between the mountain ranges to the East and West, and the Pacific Ocean and Gulf of Mexico to the South and North known as the Isthmus of Tehauntepec, which is considered the region with the highest potential for onshore and offshore wind power production (Lopez-Villalobos et al., 2018). This region on the Pacific coast is home to several wind farms as there are commonly strong Northerly winds (often referred to as the Tehuanos winds) that blow across the Isthmus of Tehuantepec (e.g., Steenburgh et al., 1998; Prósper et al., 2019), first documented by Hurd (1929). The Tehuanos winds are common, particularly in the Winter,

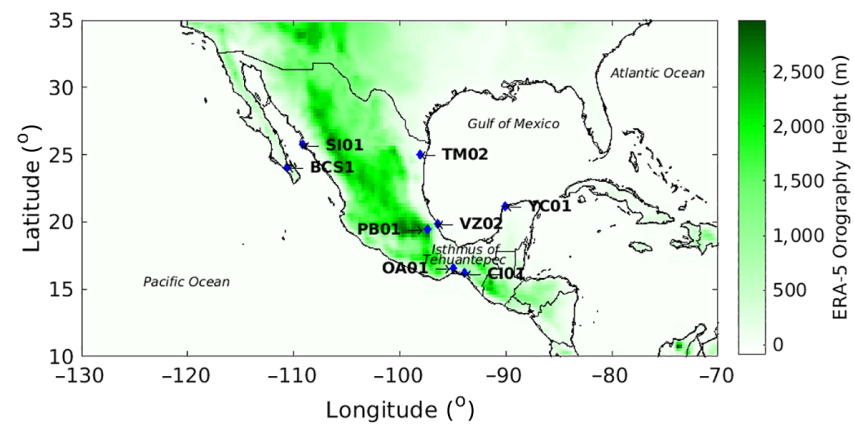

FIG URE 1 The altitude from the ERA-5 reanalysis across Mexico where the darker the shading, the higher the altitude. The locations of anemometric stations across Mexico used in this study are also shown by the diamonds and bold labels (see Table 1 for details on stations). The isthmus of Tehuantepec is labelled with the north-south aligned Chivela pass clear just north of the OA01 station and are much stronger than any winds from any other direction in this region (e.g., Barton et al., 1993; DiazMendez et al., 2010). Zavala-Hidalgo et al. (2003) showed that these strong Northerly winds are associated with the pressure difference between the Gulf of Mexico to the North and the Pacific to the South. On a larger-scale, these winds have been linked to cold surges moving down from the USA creating a strong Northerly flow across the Gulf of Mexico and through the Isthmus of Tehuantepec, mostly present during the Winter (Schultz et al., 1997a). Luna-Niño and Cavazos (2017) found that a North-Westerly jet can form in this region due to the Northerly winds interacting with the mountain ranges over Central Mexico, which can bring storm-force winds to the region. It is these sustained strong Northerly winds in the region that make this an obvious site for wind power generation.

The dominant patterns that drive winds across Mexico have not previously been explored, whereas these are commonly used in meteorological forecasting in other regions of the (e.g., Bloomfield et al., 2018; Wang et al., 2020). The literature relating to the drivers of weather in the region was summarized by Maldonado et al. (2018). Often the meteorological processes that influence Mexico are highly separated between the West and East coasts of the country. In the Winter, much of Mexico has been found to be influenced by extra-tropical systems, including cold fronts which generate strong Northerly winds across the Gulf of Mexico, related to the events in the Isthmus (e.g., Schultz et al., 1997a; Amador et al., 2006). During the Summer the East of the region is often influenced by the trade winds from the Atlantic, whereas in the West the North Pacific High pressure system (which lies consistently to the North-West of the country) moves Southwards in the summer influencing weather patterns to the North of the country's Pacific coast (Schroeder et al., 2013). Mexico has more than $9,000 \mathrm{~km}$ of coast, which are influenced by sea breezes (White and Koziara, 2018). Furthermore, the Pacific and Atlantic coasts are frequently threatened by tropical storms and hurricanes during the summer and autumn Taylor and Alfaro (2005), most commonly in regions with significant wind power infrastructure (Jáuregui, 2003), and can have the ability to damage onshore and offshore wind turbines (Rose et al., 2012).

Recent studies have investigated how winds in different regions can be utilized for wind energy purposes, however most have done so for small regions of the country. Gross and Magar (2015) used high-resolution climate data to predict the best locations for onshore wind farms for a selection of Mexican states in the North and West of the country, whereas Elliot et al. (2003) investigated the same for the state of Oaxaca in the South. A number of 
T A B LE 1 A summary of the anemometric stations used in this study, including the codes used to reference the stations throughout this article

\begin{tabular}{|c|c|c|c|c|c|c|}
\hline $\begin{array}{l}\text { Station } \\
\text { code }\end{array}$ & Region & $\begin{array}{l}\text { Latitude } \\
\text { (deg) }\end{array}$ & $\begin{array}{l}\text { Longitude } \\
\text { (deg) }\end{array}$ & $\begin{array}{l}\text { Altitude } \\
\text { (m) }\end{array}$ & $\begin{array}{l}\text { Observation } \\
\text { height } 1(\mathrm{~m})\end{array}$ & $\begin{array}{l}\text { Observation } \\
\text { height } 2(\mathrm{~m})\end{array}$ \\
\hline CI01 & Chiapas & $93^{\circ} 51^{\prime} 44^{\prime \prime} \mathrm{W}$ & $16^{\circ} 12^{\prime} 49^{\prime \prime} \mathrm{N}$ & 50 & 20 & 40 \\
\hline $\mathrm{BCS} 1$ & $\begin{array}{l}\text { Baja California Sur (san } \\
\text { Hilario) }\end{array}$ & $110^{\circ} 35^{\prime} 08^{\prime \prime} \mathrm{W}$ & $24^{\circ} 03^{\prime} 11^{\prime \prime} \mathrm{N}$ & 271 & 15 & N/A \\
\hline TM02 & Tamaulipas & $98^{\circ} 05^{\prime} 17^{\prime \prime} \mathrm{W}$ & $25^{\circ} 01^{\prime} 17^{\prime \prime} \mathrm{N}$ & 43 & 20 & 40 \\
\hline VZ02 & Veracruz & $96^{\circ} 27^{\prime} 37^{\prime \prime} \mathrm{W}$ & $19^{\circ} 51^{\prime} 32^{\prime \prime} \mathrm{N}$ & 17 & 20 & 40 \\
\hline YC01 & Yucatan & $90^{\circ} 02^{\prime} 48^{\prime \prime} \mathrm{W}$ & $21^{\circ} 09^{\prime} 53^{\prime \prime} \mathrm{N}$ & 0 & 20 & 40 \\
\hline PB01 & Puebla & $97^{\circ} 25^{\prime} 42^{\prime \prime} \mathrm{W}$ & $19^{\circ} 25^{\prime} 46^{\prime \prime} \mathrm{N}$ & 2,332 & 20 & 50 \\
\hline
\end{tabular}

studies (for example, Carrasco-Diaz et al., 2015; Magar et al., 2018) have also investigated wind power potential in some selected offshore wind sites, with the potential for significantly higher energy output than for onshore wind. Carrasco-Diaz et al. (2015) use the gridded reanalysis product BMW-CERSAT to focus on the region of Tamaulipas in the North-east of the country, whereas Magar et al. (2018) used climate models to investigate several potential offshore wind sites in their study, with an optimum location found to be to the North of the Isthmus of Tehuantepec. A recent, nationwide study of wind power availability across Mexico performed by Gallardo et al. (2020), confirmed that the most productive site for wind generation is the Isthmus of Tehuantepec. Other, less well-documented sites in the North of the country were also proposed as good sites for wind farms, given how well the wind resource compliments the solar energy resource in those regions. However, the development of new onshore wind farms in Mexico could prove difficult to implement, particularly through the Isthmus, due to the substantial legislation regarding the rights of the indigenous population (Hamister, 2012).

There has also been strong evidence linking weather in Mexico to global-scale atmospheric patterns. The El Niño Southern Oscillation (ENSO) is widely known to influence the climate of Mexico, with plenty of studies noting how ENSO influences the monsoon and hence precipitation and temperatures in Mexico (e.g., Higgins et al., 1999; Castro et al., 2001; Englehart and Douglas, 2002). On seasonal time-scales, Bravo-Cabrera et al. (2017) found a difference between precipitation in Mexico between El Niño and La Niña years which depended on seasonality, considered to be due to a southwards shift in the sub-tropical jet (STJ; Magaña et al., 2003). The influence of ENSO on the location of STJ is also important in determining whether weather systems from the North propagate into Mexico (Yu et al., 2016). Some authors have also noted differences in surface wind patterns with ENSO (e.g., Vega et al., 1998; Maldonado et al., 2018). Differences in wind speeds and the occurrence of Northerlies in the Summer through the Isthmus of Tehuantepec have been reported between El Niño and La Nina years (Romero-Centeno et al., 2003). Links between Mexican weather and the global atmospheric phenomena such as the Atlantic Multi-Decadal Oscillation (Sutton and Hodson, 2005), the Pacific Decadal Oscillation (Pavia et al., 2006), and the North Atlantic Oscillation (Santillán et al., 2012) have also been suggested (see the review by Maldonado et al., 2018). To investigate such long term variability patterns, one needs to utilize both observations, discussed next, and longer-term data sets, such as atmospheric reanalyses.

The rest of the article is organized as followed: in Section 2 , we outline the methodology including the data and reanalyses utilized in this study. In Section 3, we outline our results: identifying extreme wind events at the observation sites across Mexico, investigate the key weather patterns that drive these events and when they occur and finally link our data to ENSO. Finally, in Section 4 , we summarize our findings.

\section{2 | METHODOLOGY}

\section{1 | Observations}

In this study we utilize the UNDP-GEF wind energy sector specific data set introduced in the previous section UNDP (2012). This data set is chosen as it has reliable and consistent 10-minute resolution anemometric observations taken at one, two or three different heights, 
ranging between 10 and $80 \mathrm{~m}$ above sea-level, and are located at a variety of geographical locations. Additionally, these stations were specifically chosen for observing winds at locations with potential for wind power production and thus are clear of obstacles (such as buildings, vegetation or orography) which could influence their wind speed outputs, were in continuous operation for the whole of 2006, give a wide spread of geographical locations, and have wind speed and direction measurements at 2 heights, in most cases at 20 and $40 \mathrm{~m}$ above the ground. Most of the anemometric stations in this project are close to sea-level, meaning that they well-represent the coastal regions of the country, but less well the mountainous regions to the centre of the country.

The wind data from the sites provide data averaged every 10 minutes for the entire year. An example for the anemometric site in Chiapas, is shown in the top-right of Figure 2, where each data point is colour-coded by the quadrant in which the wind is coming from (i.e., blue is wind blowing from between North-West and NorthEast). The strongest winds are observed from the North, as seen from the blue data points which extend up to beyond $20 \mathrm{~m} / \mathrm{s}$. On the left, a histogram of wind speeds for each wind direction is shown, which is normalized by the number of data points for each direction. There are two distinct peaks for the Northerly winds, one at low wind speeds of approximately $2 \mathrm{~m} / \mathrm{s}$ and one peaking at a much higher $8 \mathrm{~m} / \mathrm{s}$. This is suggestive of two atmospheric phenomena creating these patterns. In general, the strongest Northerly winds are found in Winter, and the weaker Northerlies were seen in the Summer. Additionally, Southerly winds at this station are found to be consistently stronger than Easterly or Westerly winds. The gap in the mountains in this region is very much NorthSouth aligned and so, along with the previously documented pressure gradient (Romero-Centeno et al., 2003), there is also likely a mountain-gap outflow effect that accelerates the wind through it (Steenburgh et al., 1998). Evidence from this can be seen using observations from the North of the Isthmus (The Punta Delgado station in Veracruz) which shows much lower wind speeds throughout the year (not shown).

The lower part of Figure 2 shows a normalized histogram of the times of year in which the wind directions occur. This shows that the Northerly winds are mostly a Winter phenomenon with peaks in December and January. In contrast, the station sees more Southerlies during early Spring and then Westerlies or Easterlies during the Summer and early Autumn. The windiest times of year match neatly with the occurrence of the Northerly

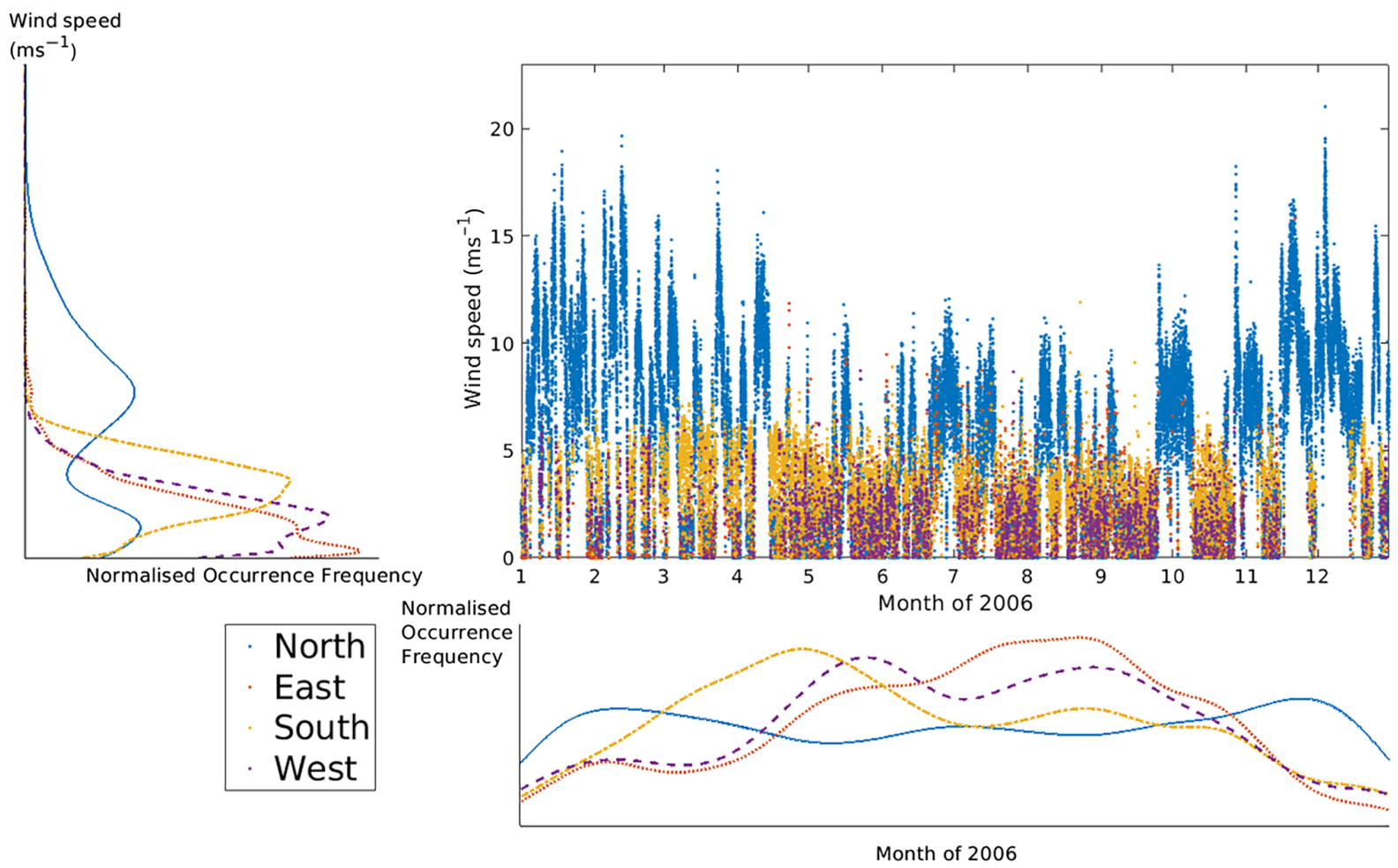

F I G U RE 2 Observations from the El Progreso weather station, Chiapas. The top-right shows a time series of wind speeds at the station, colour coded by wind direction, where blue are wind from the northerly quadrant, red from the east, yellow from the south, and purple from the west. The left shows a histogram of the wind speeds split by direction with the same colour-coding and normalized to the number of data points in each direction. The bottom is the same but for time of year 
winds, with the strongest winds observed during the Winter and Mid-Summer where a secondary peak in the frequency of Northerlies is observed. However, to explain why these different patterns occur and how they fit within the large-scale circulation, one needs longer time periods and a wider area of analysis, which is provided by atmospheric reanalyses.

\section{2 | The ERA-5 reanalysis}

In this study, we utilize the ERA-5 atmospheric reanalysis from the European Centre for Medium-range Weather Forecasts (ECMWF). Atmospheric reanalyses are long-term (typically spanning several decades), gridded data sets combining a fixed version of a numerical weather prediction model and a fixed data assimilation scheme to assimilate a consistent set of observations for the period. There are several global reanalyses available from different institutions, and some efforts have been made to investigate which is the best at reproducing wind observations in different locations (e.g., Olauson, 2018; Ramon et al., 2019), and for sites across Mexico (Thomas et al., 2020). The latter of these studies show that the ERA-5 data set from the ECMWF outperforms ERA-Interim (ECMWF) and MERRA-2 (NASA) at sites across Mexico and so is thus chosen for our study. This is deduced by interpolating horizontally from each reanalysis' grid to the locations of each of the weather stations and then vertically to the height of the observations to make comparisons. In the case of ERA-5, the correlation is found to be good with the observations for the El Progreso weather station used here (for daily resolution, the Pearson Correlation Coefficient, $R=.9$ ). ERA-5 has other advantages over other atmospheric reanalyses. It has the highest spatial resolution of about $30 \mathrm{~km}$ at the latitudes spanned by Mexico, which compares favourably to about $60 \mathrm{~km}$ for MERRA-2 and about $70 \mathrm{~km}$ for ERA-Interim. It also has an hourly temporal resolution, compared to 6-hourly for ERA-Interim. Furthermore, it has a 137 terrain-following heights compared to 72 for MERRA-2 and 60 for ERA-Interim, resulting in a higher vertical resolution (Ramon et al., 2019). Wind-component output at $100 \mathrm{~m}$ is also useful when interpolating parameters to the height of observations of wind turbines. At the time of writing, ERA-5 was available for dates between 1979 and 2019, allowing the capability to investigate wind events for the region for this 40 year period, rather than just the 1 year of observations.

However, the ERA-5 reanalyses requires postprocessing before it can be used. As alluded to in the previous paragraph, bi-linear interpolation is used to estimate the wind velocity at the location of each of the observation sites, and then a logarithmic profile is used to scale the observed wind speeds up to the height of the observations using the ERA-5 wind velocities at heights of $10 \mathrm{~m}$ and $100 \mathrm{~m}$. In doing so, a time series of ERA-5 wind velocities can be produced which can be compared to the observations (typically $40 \mathrm{~m}$ above the surface), which in turn are averaged to 6,12 and 24 hourly resolutions, using a running mean. A scatter plot of the ERA-5 interpolated wind speeds versus the observed wind speeds for the El Progreso site in Chiapas are shown in the left panel of Figure 3, where the red line shows what the perfect fit would be.

The left panel of Figure 3 clearly shows that, despite the high correlation between reanalyses and observations, the ERA-5 reanalysis is considerably underestimating wind speeds. This is particularly obvious for moderate to strong winds, whereas at low wind speeds there is a second branch to the distribution showing that in some cases the winds are over-estimated here. We therefore apply bias correction to account for this difference and to allow a one-to-one comparison between the observations and the reanalysis data sets to be utilized at the location of the observations. However, the relationship between the ERA-5 data and the observations is non-linear, meaning that a bias correction cannot be a simple linear one. The bias correction of ERA-5 winds that we apply in this study follows the quantile mapping method applied to MERRA-2 winds over the United Kingdom by Cannon et al. (2015). In this case, we fit 100 quantiles to the probability distribution functions of the ERA-5 data and observations, select the data within each quantile, and correct the mean ERA-5 data within the quantile to the distribution of the observations. This method is chosen due to the wind bias being highly variable with wind speed and by mapping the quantiles of the quantiles of the distributions, one can much more closely match the overall distribution of observed wind speeds than using less detailed methods. The result is the right panel of Figure 3. The scatter now spreads clearly around the one-to-one line. However, there is a much better fit at high wind speeds now, compared to lower winds. This is because, some low wind speed data points in the observations are overestimated by the ERA-5 data (note the group of data points to the middle-left of the figure). The cause of this could be some local effects in the observations, or some wind events that are poorly represented by the reanalysis. We find that the correlation between ERA-5 and the observations for an hourly resolution is $R=.76$ which changes very little between the non-bias corrected and bias corrected data. 


\section{3 | RESULTS}

\section{1 | Analysis of extreme wind events in Chiapas}

After applying the bias correction to the ERA-5 reanalysis, the whole 40 years of data can be used it investigate firstly the site-specific extreme events, but also the weather patterns driving the winds across the whole of the country. The extreme events are defined as the data outside of the 90th percentiles of wind speeds at the El Progreso site, Chiapas from the interpolated ERA-5 data. To avoid having consecutive data points in our data set, which would be associated with the same weather event, we first apply a 10-day mean to the data before selecting the data outside of the 90th percentiles. For each of the selected 10-day windows, we then find the highest/lowest wind speed data point within the period and use this to build a catalogue of event times, and composites of mean sea-level pressure and 10-m wind velocity vectors across the region. Table 2 shows some statistics on the events that are found using this method. There are some interesting conclusions to be deduced from the timings of the events in Table 2. Firstly, 34 out of 83 of the high speed events occurred in the most recent decade, compared with just the 24 out of 83 which took place in the first two decades combined. Furthermore, only 10 low wind speed events took place in the most recent decade, where no other decade saw less than 20 events. Whilst this is indicative of a change in the climate and similar results are found from other studies (Zeng et al., 2019), further work is require to verify whether extreme wind events are becoming more frequent. Secondly, there is a clear split in the time of the year that the

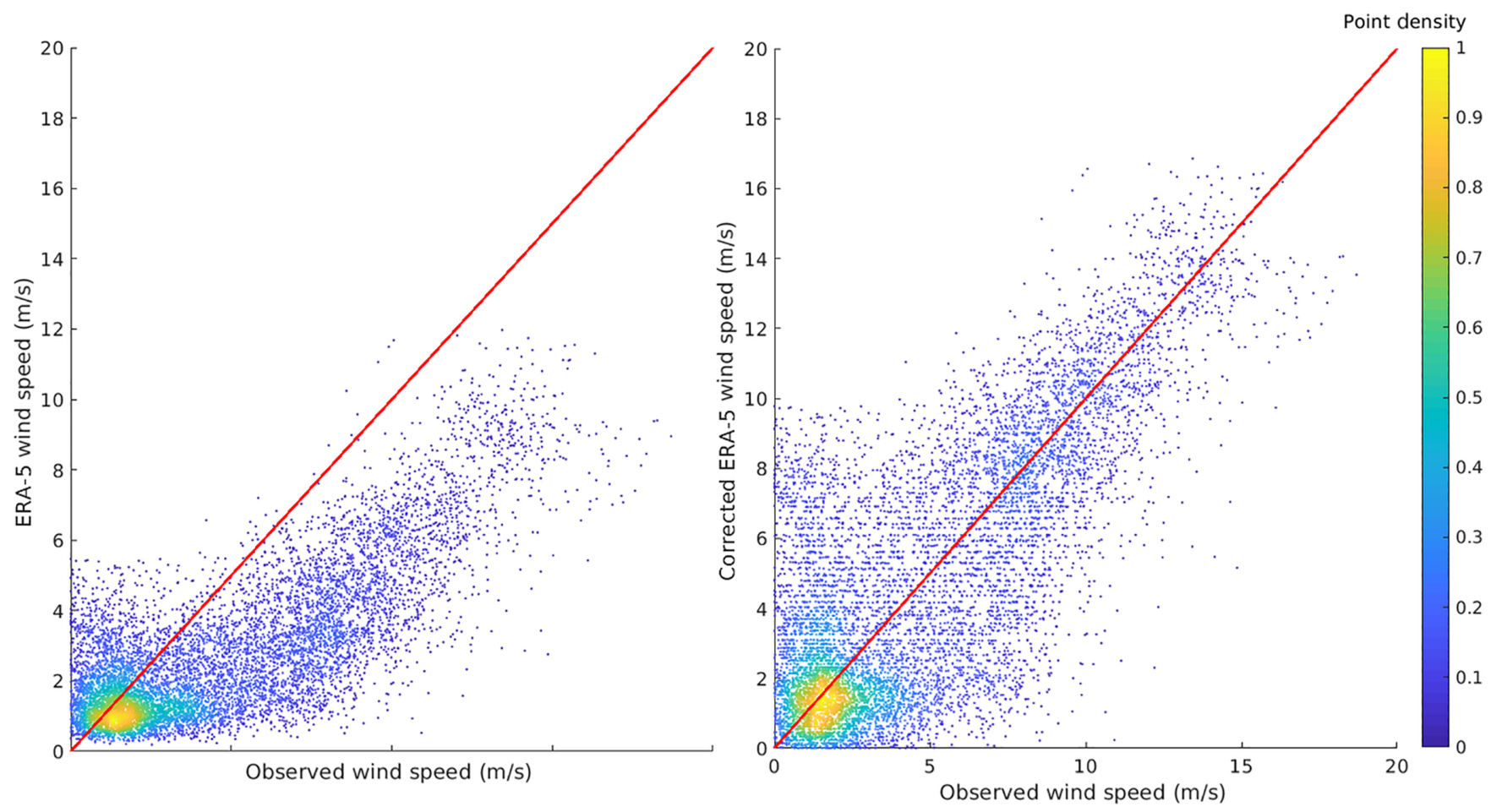

F I G U RE 3 Scatter plots of observed versus interpolated ERA-5 3-hourly wind speeds through 2006, for the El Progreso site in Chiapas. Left: ERA-5 data before bias correction. Right: Bias corrected ERA-5 data. The solid red lines show the one-to-one lines revealing that the bias corrected data is a much better fit to the observations

TA B LE 2 Times and seasons in which the top and bottom 5\% of wind speeds were recorded in Chiapas

\begin{tabular}{|llllll|}
\hline Decade & No. top events & No. bottom events & Season & No. top events & No. bottom events \\
\hline $1979-89$ & 16 & 22 & Winter & 43 & 0 \\
\hline $1990-1999$ & 8 & 20 & Spring & 3 & 51 \\
\hline $2000-09$ & 25 & 21 & Summer & 0 & 18 \\
\hline $2010-19$ & 34 & 10 & Autumn & 27 & \\
\hline
\end{tabular}


events are found within. The top wind speed events are mostly found in Winter, and whilst some are also seen in late Autumn, there are none found during the Summer. However, the low wind speed events are found predominantly in the Summer, and not at all in the Winter. Thus, the weather patterns driving the high-speed wind events are very much a Winter phenomenon and likewise the weather patterns giving low winds are a Summer phenomenon. We also investigate events where there are persistent low winds of less than $3 \mathrm{~m} / \mathrm{s}$, the threshold for wind power production at El Progreso, for more than 10 days as these would be associated with sustained periods without power production. We find 112 such events in the 40 years of data, predominantly in the Summer. Therefore, alternative power generation is often required in the Summer to supply the power not generated in the region, which needs to be found either by other methods or from wind power generation in other locations. The Summer demand for energy production would also be influenced by the need for air conditioning brought on by the intense temperatures in Mexico over the Summer months.

Figure 4 shows composites of the mean sea level pressure (shown by the contours), and wind speed vectors (the coloured arrows on top) for all of the high wind speed events combined (left panel), and all of the low wind speed events combined (right panel). The region we plot over is chosen to show the whole of Mexico and the surrounding area. This is specifically chosen to investigate the large-scale weather patterns that drive weather over Mexico, including part of the sub-tropics to the North and the tropics to the South, as well as a reasonable distance into the Pacific and Atlantic Oceans, without making the data set too big to process efficiently. The left panel of Figure 4 shows the composite of pressure and wind vectors for the times of high wind speed events at El Progreso. Here we see the North Pacific High (NPH) in the top-left close to the Baja Californian coast. There is also a rather intense high pressure system over SouthEast USA. The result is strong Northerly winds following the East coast of the USA and moving southwards across the Gulf of Mexico, plus a pressure difference of approximately $6 \mathrm{hPa}$ between the North and South of the Isthmus. Each of these help to give very strong winds through the gap in the mountains through Chiapas and Oaxaca. Note that high pressures shown across Central Mexico are related to the high altitudes in this region which are likely an artefact of the extrapolation of mean sea level pressure below the surface in these locations.

The right panel shows the same but for the low wind speed events. The NPH is in a similar location and so we suggest this is unrelated to wind speeds in Chiapas. There is, however, a significant change to the North-East of the region. The high pressure is now much weaker over South-East USA, and is now centred out into the Atlantic Ocean. The result is an Easterly flow of wind across the
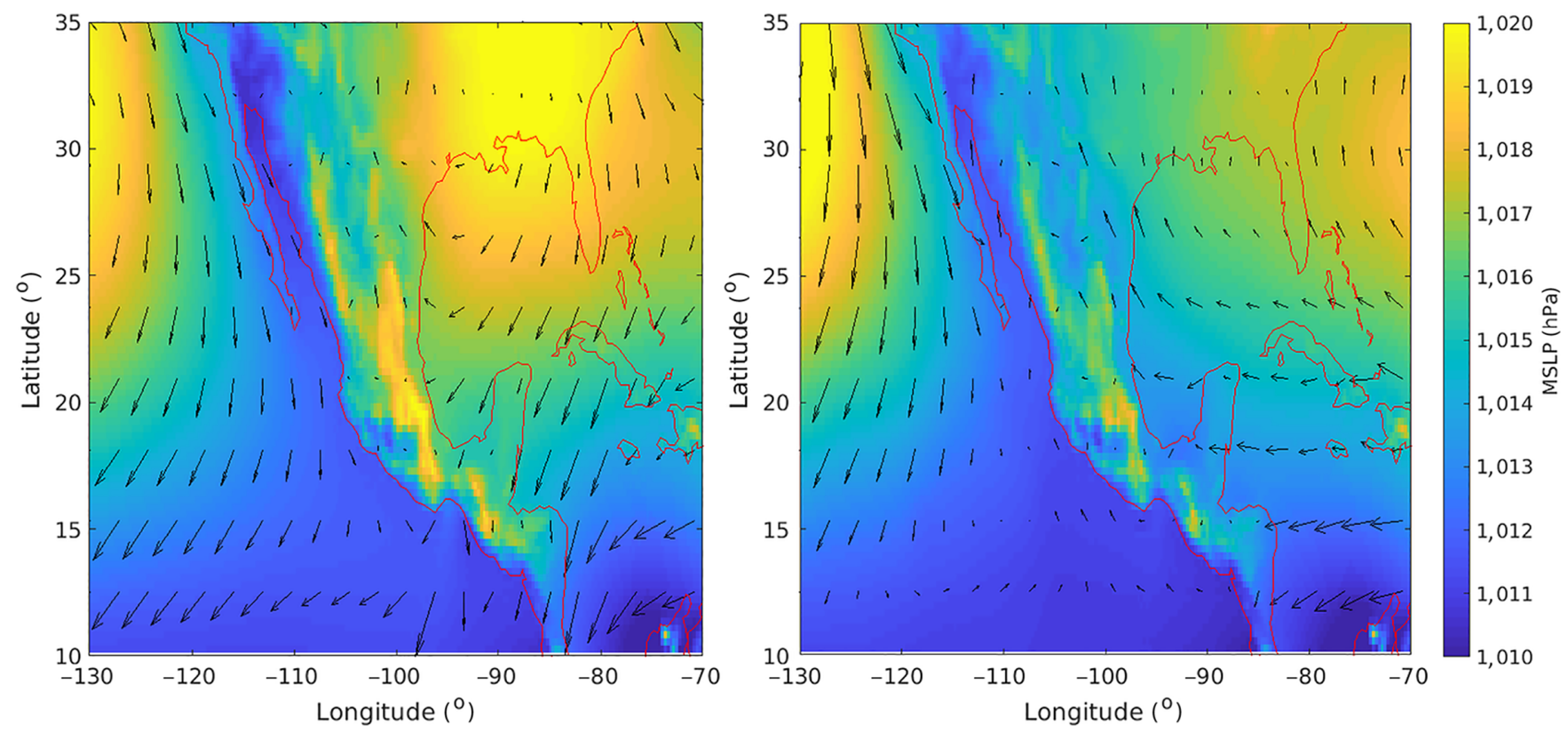

F I G U RE 4 Composites of mean sea level pressure and $10 \mathrm{~m}$ wind velocities across Mexico and the surrounding region. Left: The weather conditions including the top 5\% of wind speeds at Chiapas for all ERA-5 data. Right: The same for the bottom 5\% of wind speeds. The mean sea level pressure is mapped below with yellow indicating high pressure and blue indicating low pressure. The vectors on top show wind velocities, with the length of the arrows indicating wind speed. The red lines show the coastlines 
Caribbean and Gulf of Mexico and a low pressure difference across the Isthmus. The perpendicular flow to the gap in the mountains means that there can be no channelling of the winds, and lack of pressure gradient across the gap leading to very light winds in the region. Having established the average weather patterns associated with extreme events in the region, we now investigate the common weather patterns in the region to find the cause of such pressure patterns, using a k-means clustering algorithm.

\section{2 | Defining weather patterns from 500 hPa geopotential height}

To investigate the dominant weather patterns in Mexico, we use an empirical orthogonal function (EOF) analysis, and $k$-means clustering algorithm, in a similar manner to Sáenz and Durán-Quesada (2015) applied to Central America and Browell et al. (2018) applied to the United Kingdom. We apply this analysis to 40 years of ERA- 5 daily averaged 500-hPa geopotential heights across the domain used for the composites in Figure 4 (i.e., -70 to $-130^{\circ}$ longitude and $10-25^{\circ}$ latitude). We choose this pressure level as to be clear of any major influences from the high altitudes in Central Mexico. The first step is to remove the seasonal cycle from the 500-hPa geopotential height field so that the dominant EOF mode is not simply an expression of seasonality. The climatology of the daily-mean $500 \mathrm{hPa}$ geopotential data is removed by subtracting the monthly-mean climatology trend (i.e., the difference between the monthly mean and each data point) based on the 40 years of ERA5 data, at each grid point. Then we take EOFs of the de-trended data producing the principal components for the 9 modes that explain $95 \%$ of the variability measured by the variance. Finally, we apply a $k$-means clustering algorithm to the principal components to gain the most dominant patterns in the $500-\mathrm{hPa}$ geopotential height over the region. Using the $k$-means gap method as an accurate means of deducing the optimum number of clusters to group the weather patterns into (e.g., Tibsharani et al., 2001), we find the optimum number of clusters for the region is 8 . These weather patterns from the cluster analysis are shown in Figures 5 and 6 . Note that these are not sorted by the number of events in each weather pattern, but that the numbers are given on each panel.
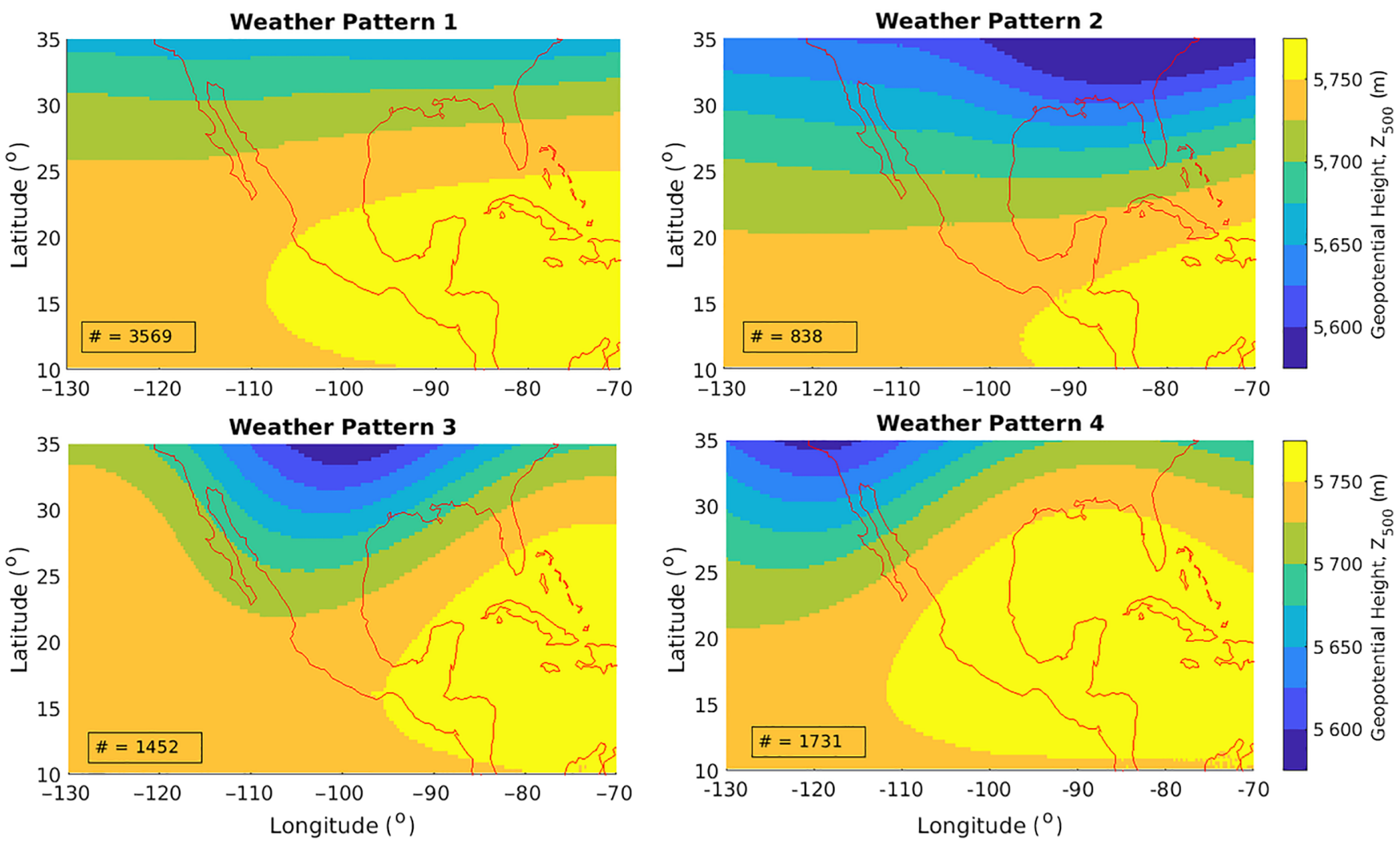

F I G U RE 5 The results of the k-means clustering on the principle components obtained from an EOF analysis on the $500 \mathrm{hPa}$ geopotential height in the region -70 to $-130^{\circ}$ longitude and $10-35^{\circ}$ latitude. Here the blue regions are lower geopotential height and the yellow are higher. The first 4 weather patterns are shown here. The number of events in each composite is shown in the bottom-left corner 

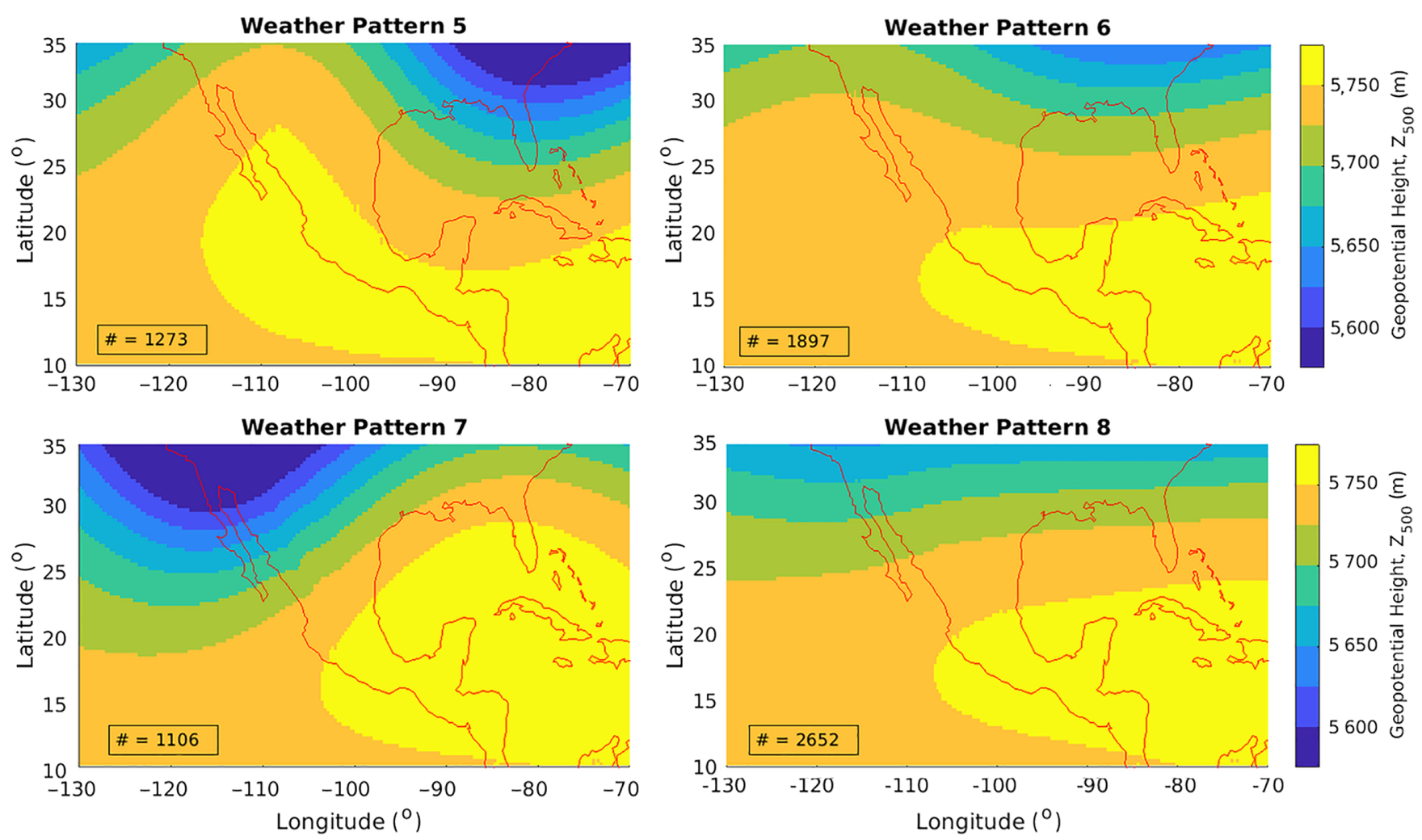

FI G URE 6 The results of the k-means clustering on the principle components obtained from an EOF analysis on the $500 \mathrm{hPa}$ geopotential height in the region -70 to $-130^{\circ}$ longitude and $10-25^{\circ}$ latitude. Here the blue regions are lower geopotential height and the yellow are higher. The second four weather patterns are shown here

Figures 5 and 6 show the geopotential height patterns for the eight clusters derived from this analysis. Unsurprisingly, in each case, the geopotential height is higher to the South and lower to the North, with a strong gradient in between associated with the sub-tropical jet (STJ; e.g., Christenson et al., 2017). However, the gradient between these varies in intensity and in shape. Weather patterns 1 and 8 have a very zonally-aligned gradient in geopotential height, whereas, for example, patterns 4,5 and 7 have a much more warped gradient, each with the passage of an upper level trough and ridge across the North of Mexico, which are associated with lower level cyclones and anticyclones. From this point on, we refer to the results of the clustering as the 8 distinct "weather patterns" for the region. Figures 7 and 8 show composites of the mean sea level pressure and 10-m wind vectors for all of the events in each of the weather patterns and are plotted in a similar manner as Figure 4. Weather patterns 1-4 are shown in Figure 7 and patterns 5-8 are in Figure 8 . The main features visible in each cluster are the $\mathrm{NPH}$ which varies in location in each pattern (for example it is situated very close to the North-West Mexican coast in weather pattern 3, but is much further away in pattern 2), the Easterly trade winds in the South-East of the region which vary in how far they reach Northwards and Westwards, and finally the high pressure systems located over South-East USA, which is highly variable between the weather patterns in size, magnitude and location.

The largest wind speed vectors around the Chivela Pass are seen in the weather pattern associated with weather pattern 5 , with the largest wind speeds seen downwind of the gap in the mountains. Similar to the composite of the high wind speed events in Figure 4, here we see Northerly winds across the Gulf of Mexico associated with a high pressure system over the Southern USA, but also a low pressure to the East of Florida. The strength of winds in the region seem very dependent on the presence of Northerly winds across the Gulf and the proximity of high pressure from the North. Thus, the winds are highly sensitive to extratropical high pressure systems coming down from the North bringing Northerly winds.

The high-speed Northerly winds across the Gulf (such as those seen in weather pattern 5 , as well as to a lesser extent pattern 2), are associated with the high pressure over the South USA and the low pressure off the East coast, and bring Northerly winds southwards from the East of the USA. Such a surface pattern is linked to the waved nature of the STJ and the trough shown in 

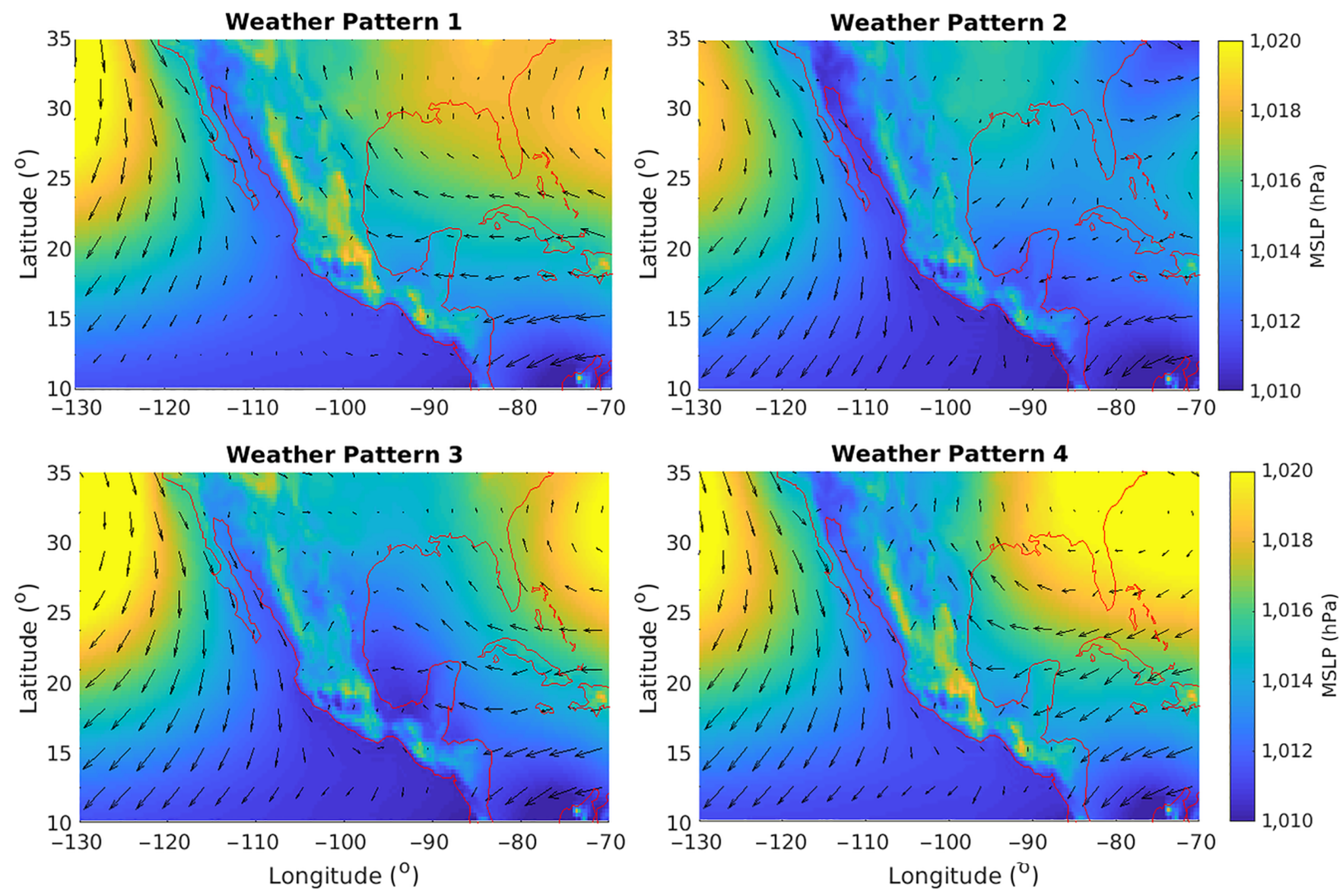

FI G URE 7 Composites of the mean sea level pressure and wind vectors for all events in each of the 4 clusters calculated from Figure 5. Here blue (darker) is lower pressure and yellow (lighter) is higher pressure. Wind vectors are shown in black on top of the composites. The first four weather patterns are shown here

the geopotential height from Figure 6. In the extra-tropics, ahead of an upper-level trough, one expects a surface cyclone, whereas behind one expects an anticyclone (e.g., Catto, 2017), like those seen in Weather Patterns 2-7 which reach the North of the region. Thus, it is the passage of this upper-level trough across the North of the country which is associated with surface-level cyclones and anticyclones which drive strong North-South aligned pressure gradients across the Gulf of Mexico. The NorthSouth gradient of the trough, and hence the proximity of the cyclone and anticyclone governs the steepness of the pressure gradient and hence the strength of the Northerly winds. Conversely, a geopotential height pattern similar to that from weather pattern 8 from Figure 8 , has little to no North-South structure and the STJ is situated far North. At the surface, this patterns shows that the high pressure over Florida is relatively week and centred far to the East, giving a very weak pressure gradient and hence weaker winds which are most affected by the Easterly trade winds to the South of the region.

Thus we summarize that the passage of an upper level trough across Northern Mexico is likely to bring high winds to the Chiapas region (as well as to the East coast of Mexico). Often such a pressure system at the system can be associated by a cold surge from an extratropical cyclone (Schultz et al., 1997a). In other weather patterns, a less wavy STJ results in fewer pressure systems influencing the South of Mexico and thus a weak Easterly flow, perpendicular to the Isthmus. We next investigate how the extreme events we have defined and fit into each weather pattern and how this varies with the time of year.

\section{3 | The seasonality of Mexican weather patterns and extreme wind events}

In this section, we consider whether each of these weather patterns are present throughout the year, or are dominant in certain seasons or month. Figure 9 shows a bar chart of the proportion of days in each month that fit into each weather pattern shown in Figures 7 and 8. Each colour represents a different weather pattern, with the light and dark blues representing the weather patterns 

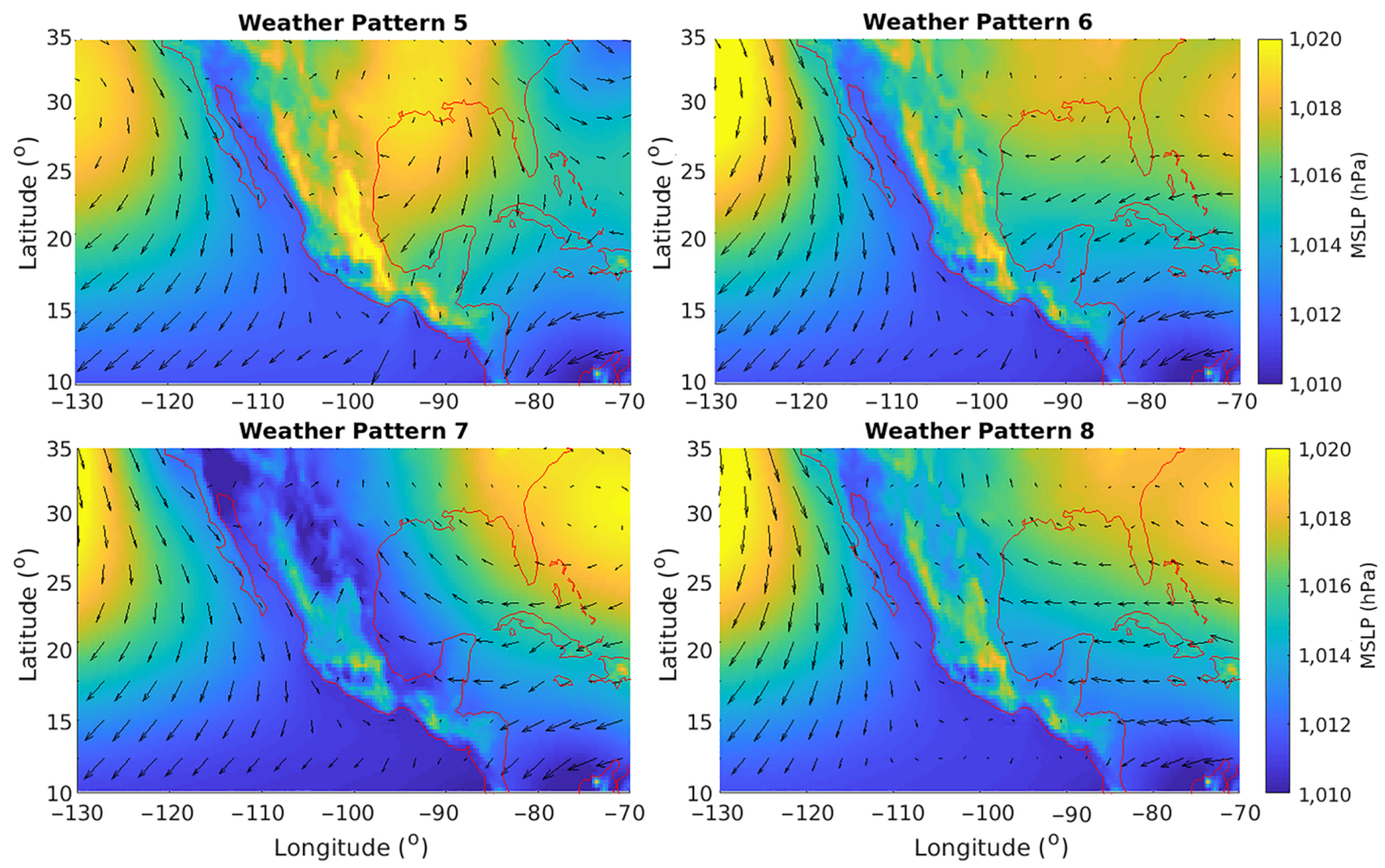

FI G U RE 8 Composites of the mean sea level pressure and wind vectors for all events in each of the 4 clusters calculated from Figure 6. Here blue is lower pressure and yellow is higher pressure. Wind vectors are shown in black on top of the composites. The second four weather patterns are shown here

FIGURE 9 The mean proportion of days in each month that fit into each weather pattern. The colours represent the weather pattern numbers, and the size of each bar is the proportion of days in that month that fit that pattern

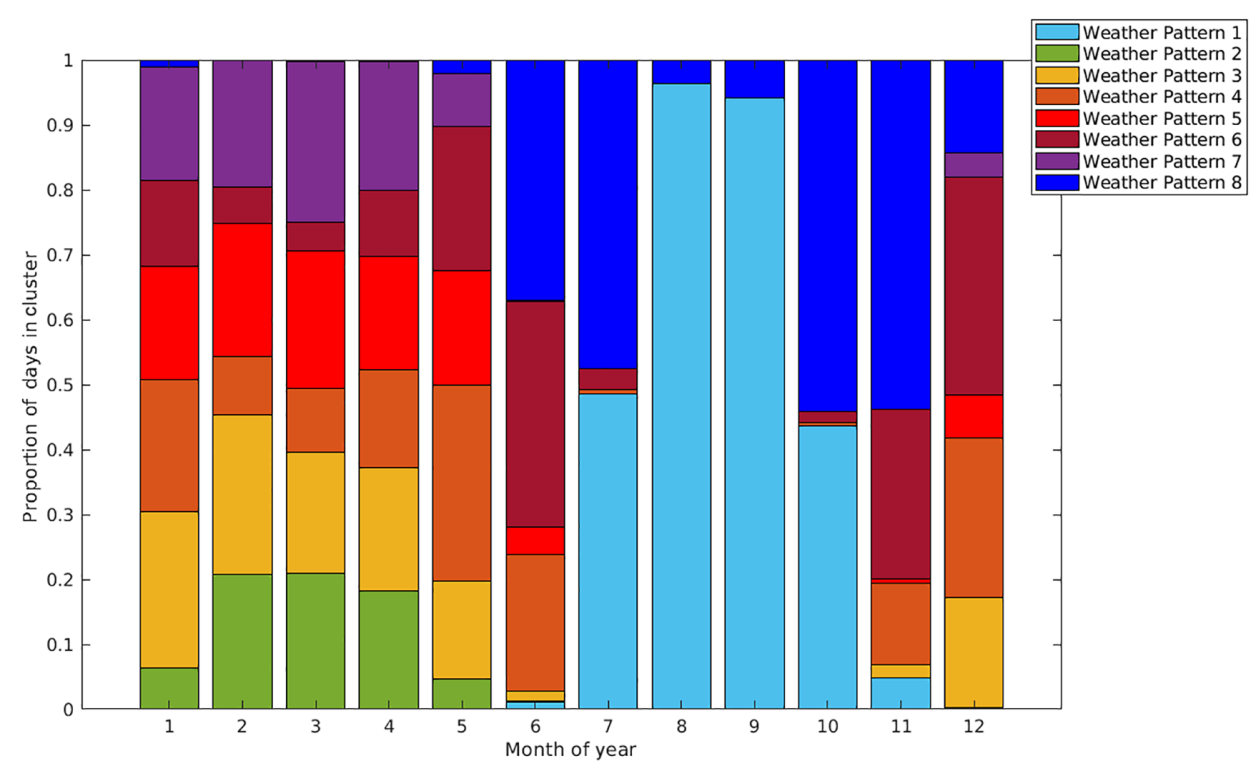

associated with the lowest wind speed events and the red showing weather pattern 5 associated with the strongest wind events in Chiapas. We see a strong seasonal shift between dominant weather patterns across the region. Between July and October, the circulation in Mexico is dominated by weather patterns 1 and 8 which are associated with a more zonal STJ and no upper-level troughs present across the region, and smaller wind vectors at the surface. In November and December, Mexico is much less likely to be in weather pattern 1 , and instead is 
dominated by weather patterns 4,6 and 8. During the rest of the year, there is a somewhat even split between weather patterns $2-7$. Whilst weather pattern 1 is only present from June to November, weather pattern 8 is non-zero for every month of the year (although the proportion of days in this cluster is very small during the Winter). Likewise, there remains a very small but finite chance of entering into weather pattern 5 with the strongest winds during the Summer.

To investigate whether this is consistent with the seasonality of our defined strong and weak wind events, we now analyse which clusters our extreme wind events fit into. This shows which of the eight most common weather patterns, if any, are likely to be associated with the strongest and weakest wind events in this region. We also apply the same analysis of the strongest and weakest wind speed events to the 7 other stations shown on Figure 1 to investigate whether the patterns causing the strongest winds at these locations are similar or dissimilar to those causing them at the El Progreso wind farm. Figure 10 shows a histogram of the highest wind speed events divided into which cluster they fit into and by the station analysed (colours).

Figure 10 shows how the top wind speed events at each of the 8 stations (locations shown in Figure 1) fit into the clusters representing the most frequent weather patterns over Mexico and the surrounding region. Here we see that the top wind events from Chiapas and Oaxaca, both in the Isthmus, have the most events lying in weather pattern 5. This is not a surprise as the wind pattern is highly similar between the high wind speed composite from Chiapas (Figure 4, left panel) and the composite of all days lying in weather pattern 5 (Figure 8 ,

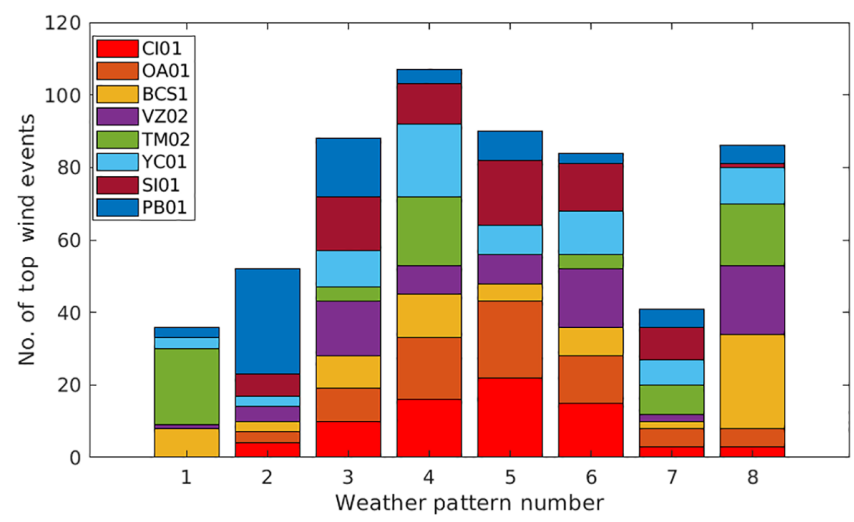

F I G U RE 10 The number of high wind events recorded at each of the eight anemometer stations (defined in Figure 1) that fit into each of the eight clusters of weather patterns over Mexico. The colours represent the eight stations, and the portions of the bars are how many of the strong wind speed events were present in that weather pattern top-left). As the Oaxaca weather station lies in a similar geographical location, it is no surprise that the events fit into the same weather patterns. There are also high wind speed events from these stations in weather patterns 4 and 6, which both display a Northerly component to the winds across the Gulf of Mexico in the composites of Figures 7 and 8. Interestingly, Sinaloa, in the North-West of Mexico, also has the most events in weather pattern 5. This is likely due to the pressure gradients over the North-West of Mexico being stronger, given the high pressure location over the South of the USA and the low over Southern California (Figure 8, top-left). However, the wind speeds on average are much lower in Sinaloa than at the sites in Chiapas and Oaxaca.

There are, however, some stations that behave rather differently. The most high speed wind events from Baja California Sur (BCS) are found in weather pattern 8. This is due to the proximity of the NPH to the peninsula, coupled with the relatively low pressure over Northern Mexico bringing strong Northerly winds along the West coast of Baja California. Notably, a similar set of weather patterns is seen from the stations on the East coast (Veracruz, Francisco Villa and Yucatan) suggesting a possible link between the large-scale weather patterns that cause the strongest winds in these areas. Figure 8 shows that weather pattern 8 has a tendency for the trade winds to dominate the weather in the East of Mexico, where there are moderate to strong Easterly winds across the majority of the region. These Easterlies are perpendicular to the gap axis at the isthmus and so we expect to see lighter winds at Chiapas and Oaxaca at this time, which we see when repeating the analysis for the low wind events in Figure 11.

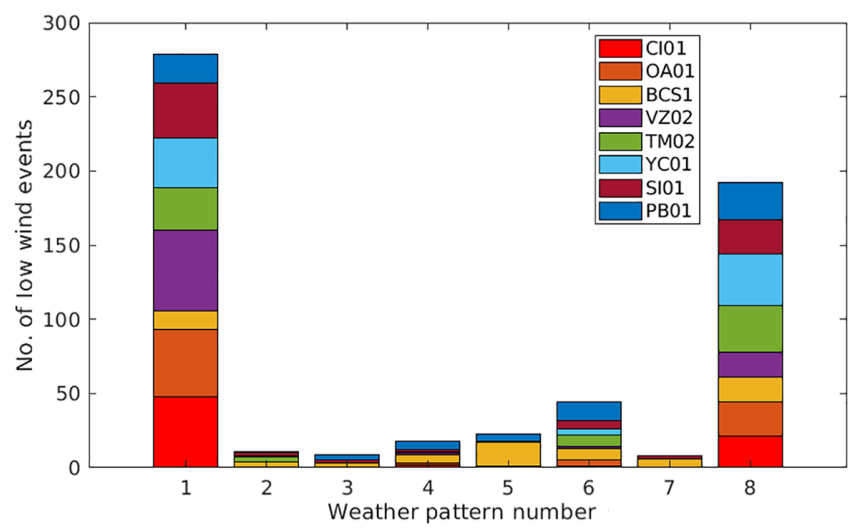

FIG URE 11 The number of low wind events recorded at each of the eight weather station (defined in Figure 1) that fit into each of the eight clusters of weather patterns over Mexico shown on Figures 7 and 8 . The colours represent the number of events for each anemometric station present in each weather pattern 
Figure 11 shows the same analysis as Figure 9, but for the low wind speed events for each weather station. For these events, there is a much higher agreement between each of the stations. For all but one of the stations, the majority of low wind speed events can be found in either weather pattern 1 or 8 . The composites in Figures 7 and 8 reveal that the weather patterns in these two composites are rather similar, with a weak high pressure system centred off of the East Coast of Florida providing a weak Easterly flow across the Gulf of Mexico. There is clearly very little wind in both cases across the Pacific coast of Central America in both clusters. However, weather pattern 8 does show stronger winds along the coast of Baja California, associated with the proximity of the NPH and the steep pressure gradient across the region, associated with the low pressure to the East of the peninsula. It is likely that this contributes to the fact that Baja California Sur is the only station that does not follow the same trend as the other observations. The highest number of low wind speed events at this station fit into weather pattern 5, which has most of the high wind speed events for Chiapas, Oaxaca, and Sinaloa, the latter of which is located on the West coast of Mexico across the strait from Baja California. This suggests that despite the proximity between the two stations, the winds are caused by very different sources. However, recent studies (MoralesRuvalcaba et al., 2020; Thomas et al., 2020) have shown that Baja California Sur stations are the least well represented stations by the interpolated ERA- 5 data, possibly due to the complex nature of the terrain over the peninsula with 2 coastlines and high and complex orography in between over the width of around $50 \mathrm{~km}$. Therefore, the differences between nearby stations might arise from the use of the ERA-5 reanalysis here.

The weather patterns that the extreme events fit into does have some important implications for wind energy purposes. The wind speeds shown in previous figures are now adjusted to wind turbine capacity factors by running through a power curve for an onshore wind turbine typical to Mexico (Lopez-Villalobos et al., 2018). The anomalies of each capacity factor at each anemometric station are then found from the respective means, and then these are normalized to account for the large difference in wind variability across the sites. Figure 12 shows a table of the corresponding results, with the data split by both weather pattern number and anemometric site. Here, the blue colours represent positive anomalies and red are negative. Whilst high speed wind events in Chiapas and Oaxaca are caused by very different weather patterns than those in Tamaulipas, Veracruz and Yucatan, on the East coast of Mexico, Figure 12 shows that wind power generation across all sites of Mexico are still on average rather low during WP 1 and 8, resulting in most of the Summer providing rather poor conditions for wind energy production. However, these periods are typically better for solar power production (Gallardo et al., 2020) which could be used to offset this problem. However, there are more issues with low wind speed events, with almost all locations experiencing very low wind speeds at the same time. Weather patterns $3,4,5$ and 7 all have positive
FI G URE 12 Table showing the mean anomalies of the capacity factor from the 2006 climatology, at each station for each of the different weather patterns. The values are colour coded by whether the anomaly is positive (blue) or negative (red) and by how large the anomaly is

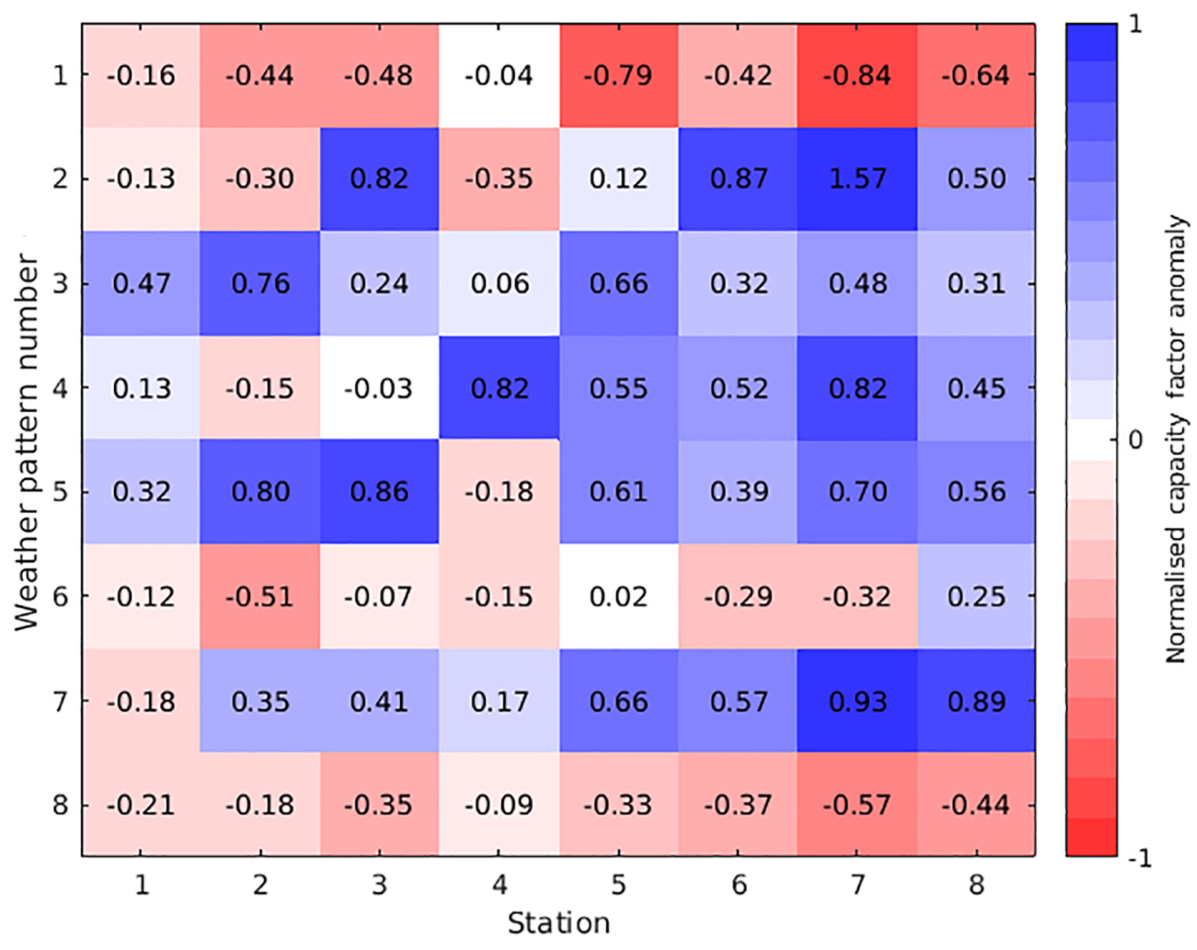


capacity factor anomalies across the majority of the sites and so are confirmed as the most likely patterns to produce wind power across Mexico. As noted in previous studies, other sites, such as Tamaulipas are found in this analysis to be excellent alternative sites to Chiapas and Oaxaca for wind power generation, whereas Sinaloa and Baja California have rather constant capacity factors between weather patterns, and much lower average wind speeds.

A full analysis of capacity factors for each grid box of ERA-5 and each weather pattern can be found in the supplementary material. Here, a notable difference is observed between weather patterns 1 and 8 , where a large region of positive capacity factor anomalies are observed along the West Coast of Baja California for WP1, which is not present in WP8, suggesting that, although the BCS1 and BCS2 sites show negative capacity factor anomalies during WP1, offshore wind sites to the West of these sites could help to compensate the lower capacity factors elsewhere at these times. One caveat is that the capacity factors anomalies calculated from ERA5 results in much larger values over the sea than land, due to low wind speeds over the land, and so some care should be taken if interpreting this data for onshore sites.

\section{4 | How persistent are wind patterns in Mexico?}

The occurrence of sustained periods of strong and weak winds also has important implications for wind power applications, as if wind turbines are not generating energy for many days in a row, other long-term energy sources will need to be utilized. We now investigate how often a theoretical wind turbine located at each of the weather station sites is likely to record sustained periods of zero or high wind energy production. For this purpose, we extrapolate the bias corrected ERA-5 winds to $80 \mathrm{~m}$ using a logarithmic profile. Wind turbines do not operate below a wind speed of $3 \mathrm{~m} / \mathrm{s}$ and so we use the assumption that a daily mean wind speed of less than $3 \mathrm{~m} / \mathrm{s}$ gives zero production (of course fluctuations in wind speed could allow for some production at different periods through the day, but these are likely to be very low). Wind power curves for the turbines used in Mexico show maximum production between 20 and $25 \mathrm{~m} / \mathrm{s}$, above which the turbines cut-out. However, these speeds are very rarely reached, especially averaging over a period of 1 day, and so for considering sustained power production, we instead use mean daily averages of above $8 \mathrm{~m} / \mathrm{s}$, situated in the transition zone of the power curve of a wind turbine. Therefore, stations with persistent winds above $8 \mathrm{~m} / \mathrm{s}$ are the better sites for wind power production and those with many persistent events of zero production would need to have other locations to keep generation going during these periods.

Figure 13 shows the persistence of high or low wind speeds at each of the eight anemometric stations locations across Mexico. For each station, the number of independent events per year (on a logarithmic scale) lasting for multiple days are shown. The left panel shows those events with persistent daily mean wind speeds of
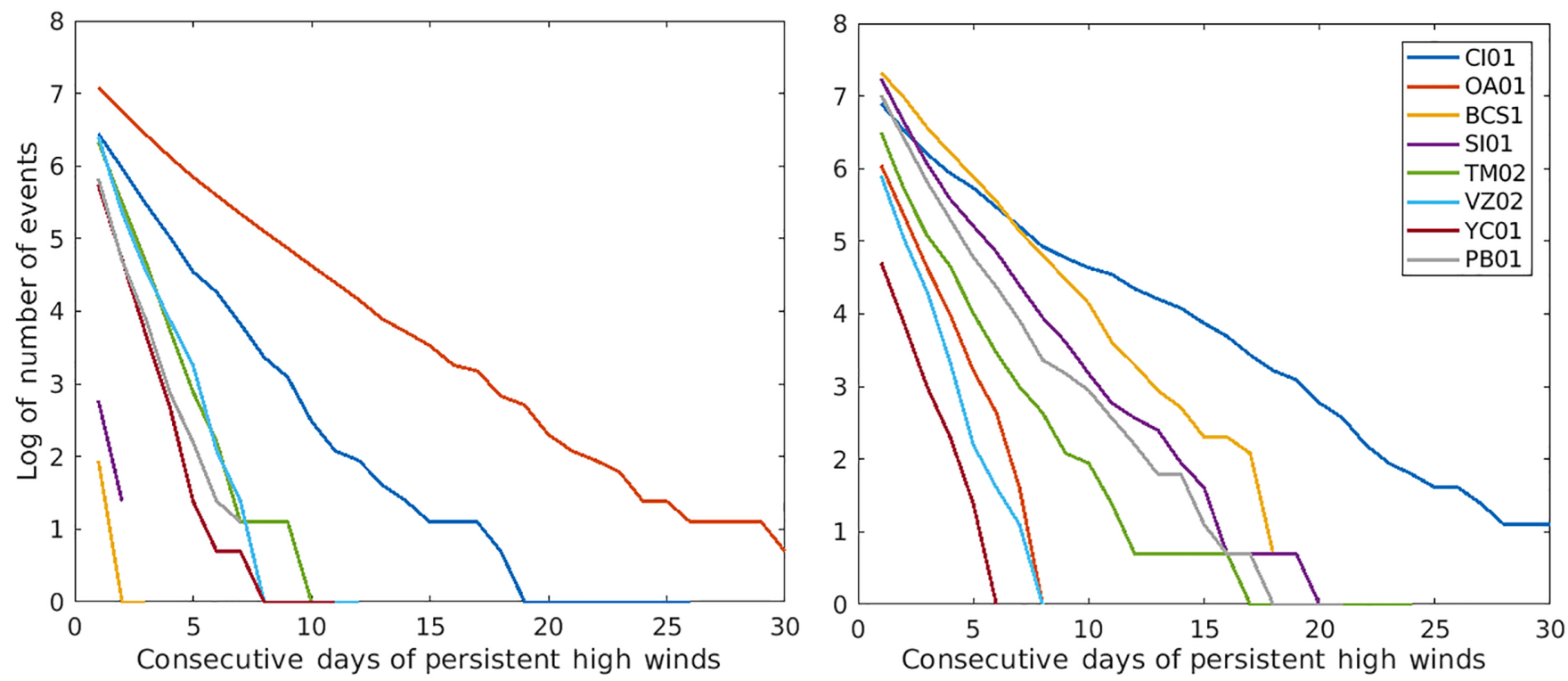

F I G U RE 13 Persistence of high (left panel) and low (right panel) wind speed events for each weather station. The plots give the logarithm (based ten) of the number of individual events throughout the 40 years of data, that last the given number of days shown on the $\mathrm{x}$ axes for each station. Each weather station is represented by a different colour 
greater than $8 \mathrm{~m} / \mathrm{s}$, whereas the right panel shows those with daily wind speeds persisting at less than $3 \mathrm{~m} / \mathrm{s}$. Some stations have many sustained events in each case, whereas some have very few. However, the fast wind cutoff was chosen as such so that all stations include some events.

The left panel of Figure 13 shows that Oaxaca (red line) has by far the largest number of persistent high wind days per year. On average, Chiapas (blue line) has around 1 event where daily mean winds exceed $8 \mathrm{~m} / \mathrm{s}$ consistently for more than 25 consecutive days every 10 years. It also has quite a few sustained low wind events. Although it has no persistent high winds in Chiapas for more than 18 days, it still experiences an average of 1 event of sustained high winds for 15 days per 10 years. Each of these cases are seen during Winter months and are associated with cold surge patterns. Baja California Sur (yellow) and Sinaloa (pink) have no sustained high wind events last any longer than 2 days. Both stations record consistently lower winds throughout the year compared to other locations and so, once the ERA-5 data is bias corrected to the observations, this is perhaps unsurprising. None of the stations outside of the Isthmus of Tehauntepec record any persistent high speed wind events lasting for more than 10 days, suggesting that the weather patterns causing the strong winds in these locations are less sustained than the cold surge patterns that drive strong Northerly winds to the Isthmus. The sustained high winds in other locations are also less confined to the Winter.
The right panel of Figure 13 shows sustained low wind speed days. Chiapas (blue) here, somewhat surprisingly, has the most frequent occurrence of persistent low winds for more than 10 days. Here, there are more than 1 persistent low wind event per 10 years, that lasts more than 25 days. These events almost entirely happen during the Summer. As can be seen in Figure 2, the El Progreso (Chiapas) station has a very seasonal pattern in wind speeds, with clear periods of high winds in the Winter, and low winds through the late Spring and Summer. This pattern is not reproduced by the Oaxaca station (red), which sees no persistent low wind events for longer than 8 days. In other regions, Sinaloa (pink), Baja California Sur (yellow) and Puebla (grey), all have persistent low winds events out to around 15 days in length. All three of these have consistently lower winds speeds than at other locations. Tamaulipas (green) has a similar number of persistent low wind events per year as it does persistent high wind events, and these can be scattered throughout the year.

Figure 14 shows a similar analysis, but for how long the weather pattern is sustained. Again the number of events per year are independent of one another and plotted on a logarithmic scale. Above a length of 5 days, weather patterns 1 and 8 (blue and grey respectively) clearly are associated with the most sustained weather patterns. Weather pattern 1 is remarkably persistent, lasting for 30 consecutive days just short of an average of once per year. As weather patterns 1 and 8 are associated with the extreme low wind speed events to all regions studied but Baja California Sur, this would result in
F I G URE 14 The persistence of each cluster number throughout the 40-years of daily wind speeds for region shown in Figures 5 and 6. The coloured lines show the number of events per year lasting for $\mathrm{N}$ consecutive days in each individual cluster, whereas the dashed black line shows the total number of events lasting $\mathrm{N}$ consecutive days irrespective of cluster number

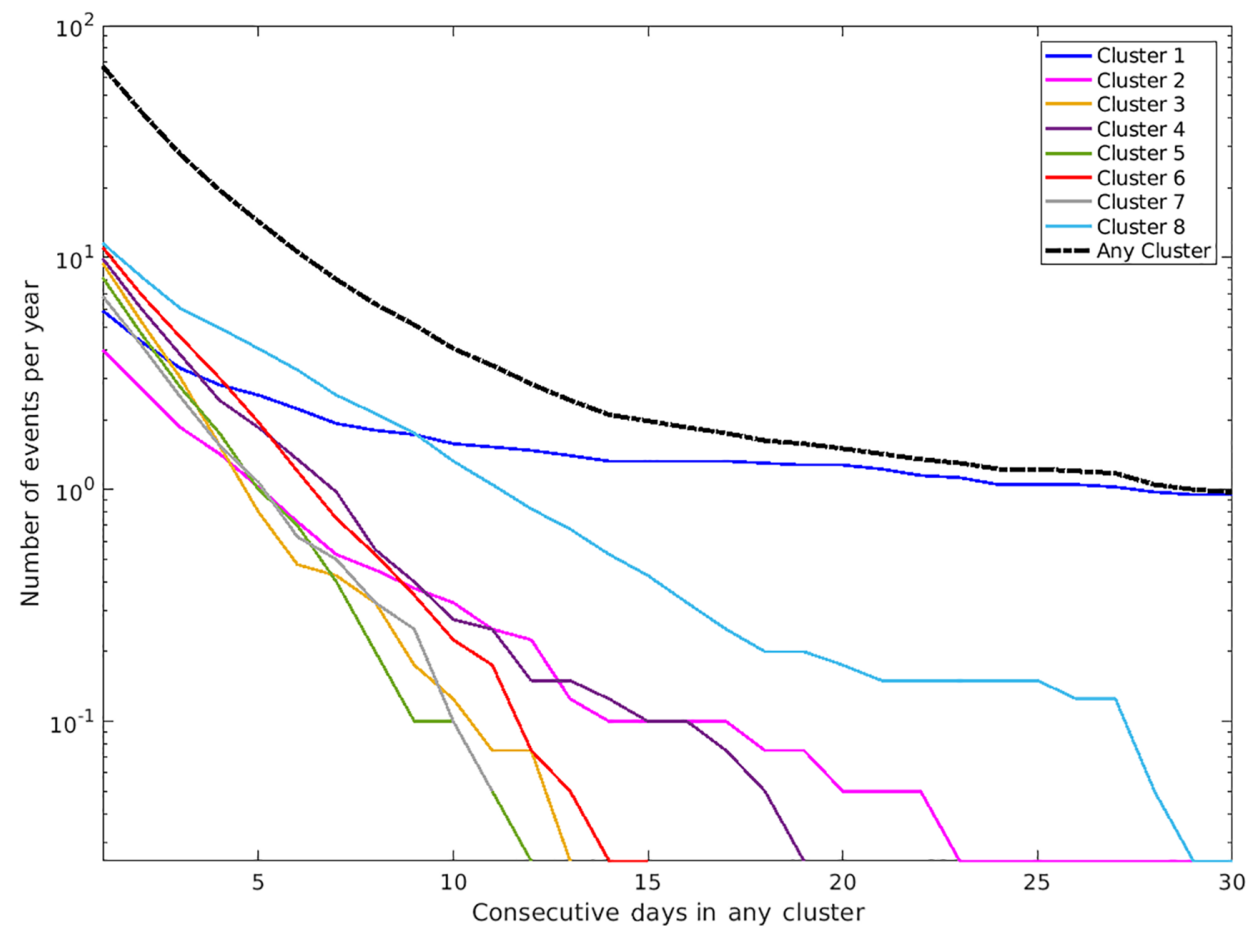


sustained low wind energy generation throughout the majority of the country for a long period of around a month per year. Note that weather pattern 1 has the second-least events in than any of the eight patterns, and so this is not simply associated with having more data points. Weather pattern 5, associated with the high speed events at Chiapas and Oaxaca, is one of the least sustained patterns, and has never persisted for longer than 12 days.

To further understand whether there are any tendencies for one weather pattern to follow another, we construct a transition matrix by comparing the weather pattern number at any given time, $t$, with the weather pattern number 2 days later. This technique is adapted from Neal et al. (2020), who investigated the patterns prior to the monsoon in India. A chart of the results is given in Figure 15, where each row is the percentage of $t+2$ days being in each weather pattern number, given the weather pattern number at day $t$ (given on the $y$-axis of the chart). Higher percentages are shown in red/pink shading whereas lower ones are shown in blue. Further evidence is shown for the persistence of weather pattern 1 , where $87.0 \%$ of days remain in pattern 1 after 2 days. Thus, from Figures 14 and 15 it is clear that once weather pattern 1 is entered, it is more often than not sustained for long periods of time, often extending beyond a month. Figure 9 showed that this pattern is only seen during the summer, and we suggest this represents a typical tropical pattern, with Easterly trade winds dominating the flow.
The vast majority of those that do depart from weather pattern 1 end in pattern 8 , which is a somewhat similar configuration, with a similar tendency for low winds across the country. However, a key difference between these two weather patterns is that pattern 1 only ever transitions to pattern 8 (with just a $0.28 \%$ change of departing of any other pattern within 2 days), whereas pattern 8 is much more likely to transition to weather patterns 4 or 6 which are associated with stronger winds across most of the anemometric sites.

Weather patterns 2 and 3 are those most likely to proceed into weather pattern 5 , which is associated with the strongest wind events for most weather stations, with percentages of 13.48 and $19.01 \%$ of events in these patterns resulting in weather pattern 5 occurring 2 days later. From Figures 5 and 6, it appears this is either associated with the passage of an upper level trough from West to East (weather pattern 3) or from the southward propagation of an existing upper level trough (weather pattern 2). Furthermore, weather pattern 7 often precedes pattern 3 which provides further evidence for the passage of the upper level trough across the southern USA being associated with the production of the strongest winds across the region.

\subsection{El Niño and Mexican wind patterns}

We finally will investigate the influence of the large-scale meteorological phenomenon, the EL Niño Southern

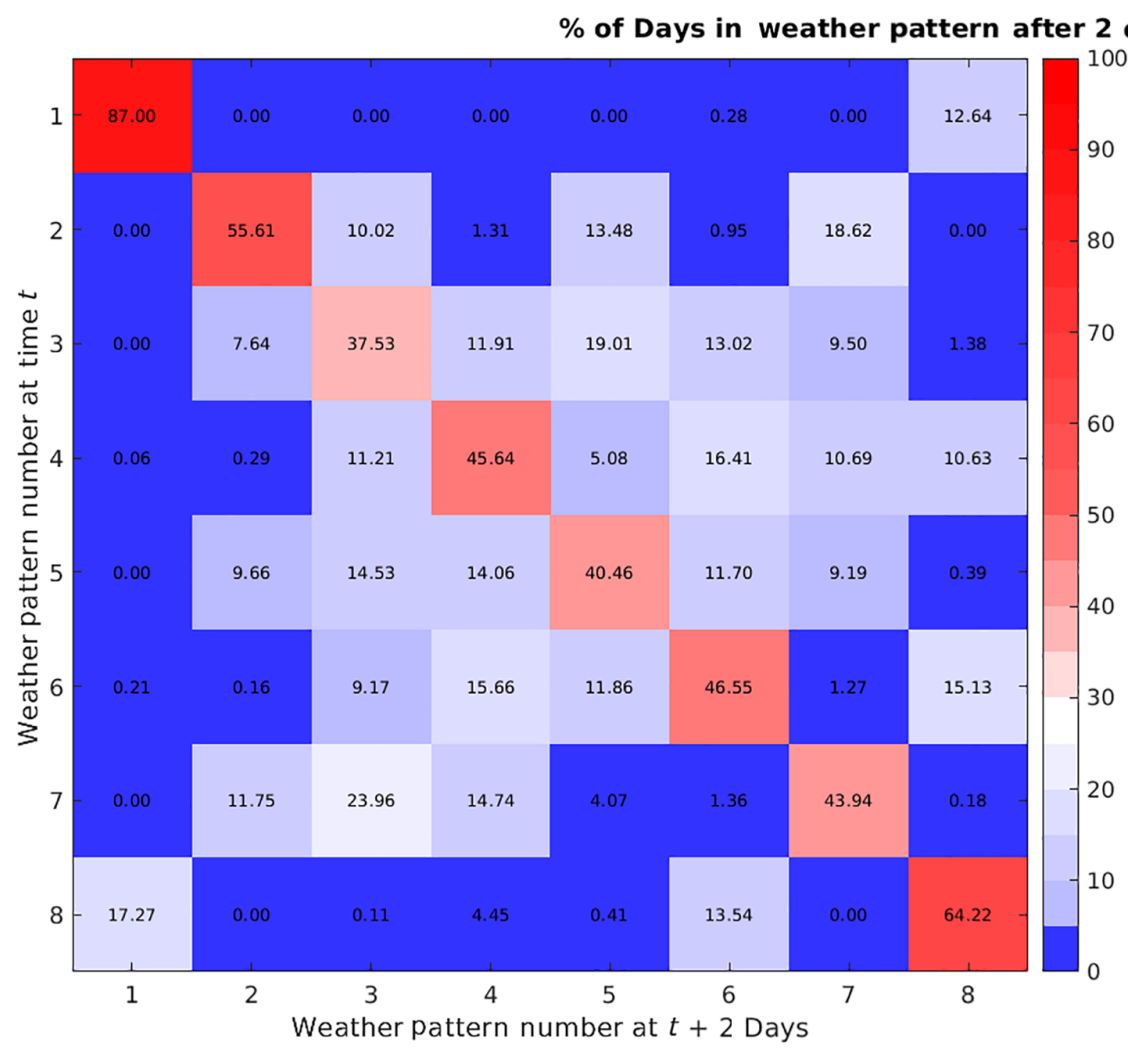

F I G URE 15 Table showing which clusters the $500 \mathrm{hPa}$ geopotential height fit in 2 days after any given date. The rows give the cluster number at any given time, $t$, and the columns are the cluster number 2 days after this date. The values are the percentage of all days starting in that weather pattern that end up in the pattern given by each column (i.e., $17.27 \%$ of days in weather pattern 8 will be followed 2 days later by a day in weather pattern 1). The red/pink have larger number of instances present in that cell, whereas the darker blue have the smallest number 
Oscillation (ENSO) impacts these weather patterns to give a broader explanation for the causes of extreme winds events in Mexico. Here we use the monthly NOAA ENSO Index to compare against monthly mean wind speeds from the ERA-5 reanalysis. Combining all data shows no statistical correlations between the EL Niño index and observed wind speeds at any of the weather stations used in this study. However, Romero-Centeno et al. (2003) used a monthly ENSO index from the Japanese Meteorological Agency to compare with modelled wind speeds through the Isthmus of Tehauntepec and found some inter-annual differences between the winds speeds and direction in the region between El Niño and La Nina years. Here we use a similar method, instead updating to use 40 years of ERA-5 data interpolated to each of the wind speed observations across the country and comparing times when the NOAA ENSO index was above 0.5 (defined as El Niño months) or below -0.5 (defined as La Niña months), as well as times when the index was neutral (i.e., between -0.5 and 0.5 ). The wind speeds separated in this way by ENSO index is shown in Figure 15, where red are El Niño times, Blue are La Niña times, and black are neutral times.

Figure 16 shows the means of all months of data split by the ENSO index. For most stations, most months have very little differences between times of El Niño and La Niña events. However, there are some key differences. Chiapas and Oaxaca (top left panels) show stronger winds on average through the summer during El Niño events than neutral or La Niña events. This is particularly apparent for Oaxaca where there is an approximately 2-3 m/s difference in wind speed for June, July and August. A difference was also noted by Romero-Centeno et al. (2003) where their modelled data showed a difference in August between the different conditions. This coincides with a difference in the percentage of Northerly winds during the summer between El Niño and La Niña months, with more Northerlies observed during El Niño months. More cold frontal passages across the South of Mexico have been reported by Schultz et al. (1997b) during El Niño summers, which are likely to cause this difference in wind directions and hence increased channelling through the gap in the mountains.

There are also some other periods at different stations which show differences. Sinaloa(Figure 15e) shows that wind speeds are stronger during La Niña months between May and August than during El Niño months. There are also stronger wind speeds during La Niña than El Niño months in Tamaulipas and Veracruz (Figure 15b and d) from December until May. Finally, the winds at
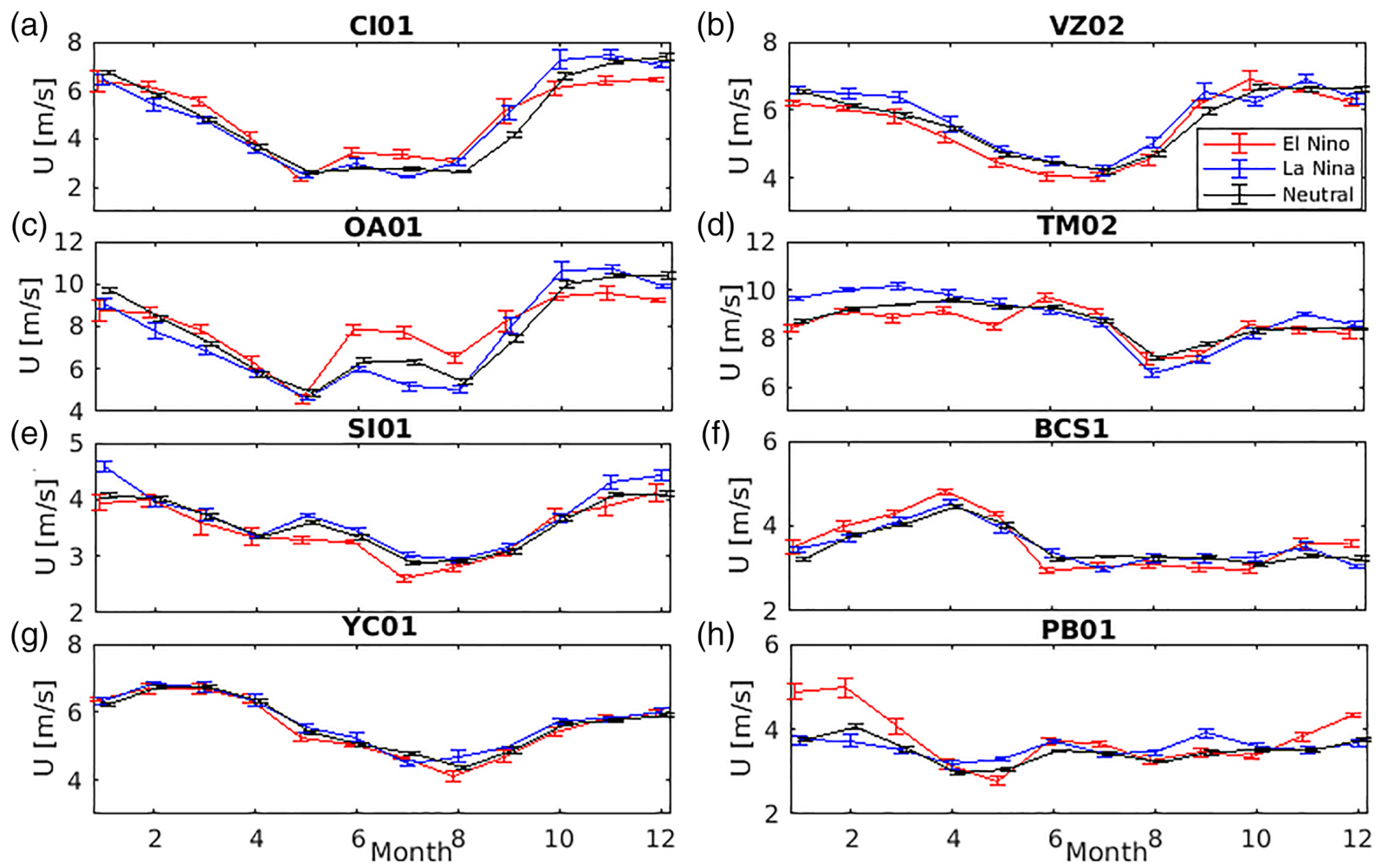

F I G U RE 16 Monthly mean wind speeds from the ERA-5 reanalyses interpolated to each location of each anemometric station and split by the monthly NOAA ENSO index. Here, El months are those with an ENSO index of greater than 0.5 (shown in red) and La Nina months are those with an index of less than -0.5 (shown in $b$, whereas neutral months are in between these values and shown in black 
Puebla (Figure 15(h)) during El Niño months during the Winter are $20 \%$ stronger than during La Niña months. This is not something seen at any other station, and could well be due to the high altitude of the station.

\section{4 | CONCLUSIONS AND WIND POWER APPLICATIONS}

In this study, we have determined the dominant weather patterns in Mexico using a k-means clustering algorithm and how the strongest and weakest wind speeds observed at anemometric sites across Mexico are related to these. Our results show that the strongest winds across most of Mexico are linked to a number of dominant weather patterns, for example, cold surges which can bring storm force winds to the Isthmus of Tehuantepec. However, the weather patterns associated with the strongest winds to Chiapas and Oaxaca in the South are not the same as those associated with the strongest winds to the East coast of the country where the majority are associated with a strengthening of the Easterly trade winds. Generally the biggest difference between the dominant weather patterns found in this study are the location and depth of the anticyclone to the North-East of the region, and the presence and locations of troughs and ridges in upper levels in the atmosphere that drives the surface cyclones and anticyclones over the South of the USA.

For low wind speed events, there is much more agreement between the stations with all weak wind events occurring associated with the same weather patterns for 7 out of our 8 sites. These events for the region are associated with a weaker Easterly flow across the Gulf of Mexico, perpendicular to the gap in the mountains. The vast majority of low wind events were seen when both the STJ is much to the North of the country and a shallow anticyclone is located to the North-East of Florida. In this scenario, no extra-tropical storms influence the Isthmus region, and thus are unable to influence the pressure difference across it to strengthen the winds. The outlier is the Baja California Sur site with the weakest wind events found within the same weather pattern as the strongest wind events at Chiapas (and vice-versa). Here the influence of the NPH is more important to the wind patterns, as well as the proximity of a low pressure system to the North of Mexico. Unfortunately, this tendency is not seen when investigating the mean capacity factors or wind farms across Mexico, where lower than average power generation is observed in these patterns across all sites.

The influence of ENSO on winds across Mexico is small. However, on sub-seasonal time-scales, there are some notable differences between El Niño and La Niña times. Summer wind speeds at Oaxaca and Chiapas are stronger during El Niño times than La Niña times, associated with there being more frequent cold frontal passages across Southern Mexico bringing more Northerly winds during these months. We report for the first time, the opposite response of wind speeds in Sinaloa, towards the NorthWest of Mexico. Furthermore, in the Winter and early Spring, East coast stations (in the regions of Tamaulipas and Veracruz) show stronger winds during La Niña years.

To mitigate against times of sustained low wind speeds, and similarly to make the most of times of high and sustained wind speeds, it is important for wind farms to be located in areas which are influenced by different weather patterns. Weather patterns 1 and 8, observed predominantly during the summer are associated with low wind production across all sites, compared to the annual mean. However, weather patterns 3, 4, 5 and 7 are associate with higher than average wind power production across most sites. The strongest winds and hence largest capacity factors are found to occur in different weather regimes to one another, meaning that wind farms in other regions to the Isthmus of Tehuantepec could help to increase wind power production across the country.

\section{ACKNOWLEDGEMENTS}

This research was supported by a Newton Fund Institutional Links grant, ID 432335407, funded by the UK Department of Business, Energy and Industrial Strategy and delivered by the British Council, and by the UK National Centre for Atmospheric Science through the Atmospheric hazard in developing Countries: Risk assessment and Early Warning (ACREW) project.

\section{ORCID}

Simon Richard Thomas (1D) https://orcid.org/0000-00017119-9545

Oscar Martínez-Alvarado (D) https://orcid.org/0000-00025285-0379

\section{REFERENCES}

Amador, J., Chacon, E., Lizano, O. and Magana, V. (2006) Atmospheric forcing of the eastern tropical Pacific: a review. Progress in Ocean, 69, 101-142.

Barton, E., Argote, M., Brown, J., Kosro, P., Lavin, M., Robles, J., Smith, R., Trasviña, A. and Velez, H. (1993) Supersquirt: dynamics of the Gulf of Tehuantepec, Mexico. Oceanography, $6,23-30$.

Bloomfield, H., Brayshaw, D.J., Shaffrey, L., Coker, P.J. and Thornton, H.E. (2018) The changing sensitivity of power systems to meteorological drivers: a case study of Great Britain. Environmental Research Letters, 13(5), 054028

Bravo-Cabrera, J., Azpra-Romero, E., Zarraluque-Such, V. and GayGarcia, C. (2017) Effects of El Niño in Mexico during rainy and dry seasons: an extended treatment. Atmosfera, 30(3), 221-232. 
Browell, J., Drew, D.R. and Philippopoulos, K. (2018) Improved very short-term spatio-temporal wind forecasting using atmospheric regimes. Wind Energy, 21, 968-979.

Cannon, D., Brayshaw, D., Methven, J., Coker, P. and Lenaghan, D. (2015) Using reanalysis data to quantify extreme wind power generation statistics: a 33 year case study in Great Britain. Renewable Energy, 75, 767-778.

Carrasco-Diaz, M., Rivas, D., Orozco-Contreras, M. and SanchezMontante, O. (2015) An assessment of wind power potential along the coast of Tamaulipas, northeastern Mexico. Renewable Energy, 78, 295-305.

Castro, C., McKee, T. and Pielke, R. (2001) The relationship of the north American monsoon to tropical and North Pacific Sea surface temperatures as revealed by observational analyses. Journal of Climate, 14, 4449-4473.

Catto, J. (2017) Extratropical cyclone classification and its use in climate studies. Reviews of Geophysics, 30(2), 486-520.

Christenson, C., Martin, J. and Handlos, Z. (2017) A synoptic climatology of northern hemisphere, cold season polar and subtropical jet superposition events. Journal of Climate, 30, 7231-7246.

Diaz-Mendez, G., Lehner, S., Ocampo-Torres, F., Ming Li, X. and Brusch, S. (2010) Wind and wave observations off the South Pacific coast of Mexico using TerraSAR-X imagery. International Journal of Remote Sensing, 31, 4933-4955.

Elliot, D., Schwartz, M., Scott, M., Haymes, S., Heimiller, S. and George, R. (2003) Wind energy resource Atlas of Oaxaca. USA Tecnhical Report.

Englehart, P.J. and Douglas, A.V. (2002) Mexico's summer rainfall patterns: an analysis of regional modes and changes in their teleconnectivity. Atmosfera, 15(3), 147-164.

Gallardo, R.P., Ríos, A.M. and Ramírez, J.S. (2020) Analysis of the solar and wind energetic complementarity in Mexico. Journal of Cleaner Production, 268, 122323.

Gross, M.S. and Magar, V. (2015) Offshore wind energy potential estimation using UPSCALE climate data. Energy Science \& Engineering, 3, 342-359.

Hamister, L. (2012) Wind development of Oaxaca, Mexico's isthmus of Tehuantepec: energy efficient or human rights deficient? Mexican Law Review, 5(1), 151-179.

Higgins, R., Chen, Y. and Douglas, A. (1999) Interannual variability of the north American warm season precipitation regime. Journal of Climate, 12, 653-680.

Hurd, H. (1929) Northers of the Gulf of Tehuantepec. Monthly Weather Review, 57, 192-194.

Jáuregui, E. (2003) Climatology of landfalling hurricanes and tropical storms in Mexico. Atmosfera, 16(4), 193-204.

Lopez-Villalobos, C.A., Rodriguez-Hernandez, O., CamposAmezcua, R., Hernandez-Cruz, G., Jaramillo, O.A. and Mendoza, J.L. (2018) Wind turbulence intensity at La Ventosa, Mexico: a comparative study with the IEC61400 standards. Energies, 11(11), 3007.

Luna-Niño, R. and Cavazos, T. (2017) Formation of a coastal barrier jet in the Gulf of Mexico due to the interaction of cold fronts with the Sierra Madre oriental mountain range. Quarterly Journal of the Royal Meteorological Society, 144, 115-128.

Magaña, V., Vazquez, J., Perez, J. and Perez, J. (2003) Impact of El Niño on precipitation in Mexico. Geofisica Internacional, 42(3), 313-330.
Magar, V., Gross, M. and Gonzales-Garcia, L. (2018) Offshore wind energy resource assessment under techno-economic and socialecological constraints. Ocean \& Coastal Management, 152, 77-87.

Maldonado, T.E., Alfaro, J. and Hidalgo, H.G. (2018) A review of the main drivers and variability of central Americas's climate and seasonal forecast systems. Bio Tropic, 66, 153-175.

Morales-Ruvalcaba, C., Martinez-Alvarado, O., RodriguezHernandez, O., Drew, D. and Ramos, E. (2020) Analysis of capacity factors related to wind power generation in Mexico using reanalysis data. Energy for Sustainable Development, 58, 158-166.

Neal, R., Robbins, J., Dankers, R., Mitra, A., Jayakumar, A., Rayagopal, E.N. and Adamson, G. (2020) Deriving optimal weather pattern definitions for the representation of precipitation variability over India. International Journal of Climatology, 40, 342-360.

Olauson, J. (2018) ERA5: the new champion of wind power modelling? Renewable Energy, 126, 322-331.

Pavia, E., Graef, F. and Reyes, J. (2006) PDO-ENSO effects in the climate of Mexico. Journal of Climate, 19, 6433-6438.

Prósper, M., Sosa Tinoco, I., Otero Casal, C. and Miguez-Macho, G. (2019) Downslope windstorms in the isthmus of Tehuantepec during Tehuantepecer events: a numerical study with WRF high-resolution simulations. Earth System Dynamics, 10, 485-499.

Ramon, J., Lledó, L., Torralba, V., Soret, A. and Doblas-Reyes, F.J. (2019) What global reanalysis best represents near-surface winds? Quarterly Journal of the Royal Meteorological Society, 145, 3236-3251.

Romero-Centeno, R., Zavala-Hidalgo, J., Gallegos, A. and O'Brien, J.J. (2003) Isthmus of Tehuantepac wind climatology and ENSO signal. Journal of Climate, 16, 2628-2639.

Rose, S., Jaramillo, P., Small, M. and Grossman, I. (2012) Quantifying the hurricane risk to offshore wind turbines. Proceedings of the National Academy of Sciences of the United States of America, 109(9), 3247-3252.

Sáenz, F. and Durán-Quesada, A.M. (2015) A climatology of low level wind regimes over Central America using a weather type classification approach. Frontiers in Earth Science, $3(15)$.

Santillán, N., López, R., Zepeda, R. and Treja, R. (2012) Climate change in NE Mexico: influence of the North Atlantic oscillation. Investigaciones Geográficas, 78.

Schroeder, I., Black, B., Sydeman, W., Bograd, S., Hazen, E., Santora, J. and Wells, B. (2013) The North Pacific high and wintertime pre-conditioning of California current productivity. Geophysical Research Letters, 40, 541-546.

Schultz, D., Bracken, W. and Bosart, L. (1997a) Planetary and synoptic scale signatures associated with central American cold surges. Monthly Weather Review, 126(1), 5-27.

Schultz, D., Bracken, W., Bosart, L., Hakim, G., Bedrick, M., Dickinson, M. and K.R., T. (1997b) The 1993 superstorm cold surge: frontal structure, gap flow and tropical impact. Monthly Weather Review, (1), 5-39.

Steenburgh, W.J., Schultz, D.M. and Colle, B.A. (1998) The structure and evolution of gap outflow over the Gulf of Tehuantepec, Mexico. Monthly Weather Review, 126, 2673-2691. 
Sutton, R. and Hodson, D. (2005) Atlantic Ocean forcing of north American and European summer climate. Science, 309, 115-118.

Taylor, M. and Alfaro, E. (2005) Climate of Central America and the Caribbean. Netherlands: Springer.

Thomas, S., Nicolau, S., Martinez-Alvarado, O. and Drew, D. (2020) How well do atmospheric reanalyses reproduce observed winds in Mexico? Met. Apps, In Press.

Tibsharani, R., Walther, G. and Hastie, T. (2001) Estimating the number of clusters in a data set via the gap statistic. Journal of the Royal Statistical Society, 63(2), 411-423.

UNDP (2012 Plan de acción para eliminar barreras para la implementación en gran escala de la energía eólica en México. [Accessed 1st June, 2020].

van der Wiel, K., Bloomfield, H., Lee, R.W., Stoop, L., Blackport, R., Screen, J. and Selten, F.M. (2019) The influence of weather regimes on European renewable energy production and demand. Environmental Research Letters, 14(9), 094010.

Vega, A., Rohli, R. and Henderson, K. (1998) The Gulf of Mexico mid-tropospheric response to El Niño and La Niña forcing. Climate Research, 10, 115-125.

Wang, M., Ullrich, P. and Millstein, D. (2020) Future projections of wind patterns in California with the variable-resolution CESM: a clustering analysis approach. Climate Dynamics, 54, 2511-2531.

White, L.D. and Koziara, M. (2018) Surface thermodynamic gradients associated with Gulf of Mexico Sea-breeze fronts. Advances in Meteorology, 18(9), 1-18.
Yu, L., Zhong, S., Hellmen, W. and Bian, X. (2016) The effect of two types of El Niño on the southerly low-level jets in North America. Earth and Space Science, 3, 306-317.

Zavala-Hidalgo, J., Morey, S. and O'Brien, J. (2003) Seasonal circulation on the western shelf of the Gulf of Mexico using a highresolution numerical model. Journal of Geophysical Research, Oceans, 108(C12), 3389-3408.

Zeng, A., Ziegler, A.D., Searchinger, T., Yang, L., Chen, A., Ju, K., Piao, S., Li, L.Z.X., Ciais, P., Chen, D., Liu, J., AzorinMolina, C., Chappell, A., Medvigy, D. and Wood, E.F. (2019) A reversal in global terrestrial stilling and its implications for wind energy production. Nature Climate Change, 9, 979-985.

\section{SUPPORTING INFORMATION}

Additional supporting information may be found online in the Supporting Information section at the end of this article.

How to cite this article: Thomas SR, MartínezAlvarado O, Drew D, Bloomfield H. Drivers of extreme wind events in Mexico for windpower applications. Int J Climatol. 2021;41 (Suppl. 1): E2321-E2340. https://doi.org/10.1002/joc.6848 